\title{
Identificação de Alterações em Conectividades Funcionais Córtico-Cerebelares no Transtorno do Espectro Autista
}

\author{
Taiane Coelho Ramos \\ DissertaÇÃo Apresentada \\ $\mathrm{AO}$
}

Instituto De Matemática e Estatística

DA

Universidade DE SÃo PAUlo

COMO REQUISITO PARA

OBTENÇÃO DO TÍTULO

DE

Mestre em CiênCIAS

Programa: Pós-graduação em Ciência da Computação

Orientador: Prof. Dr. André Fujita 


\section{Identificação de Alterações em Conectividades Funcionais Córtico-Cerebelares no Transtorno do Espectro Autista}

Esta versão da dissertação contém as correções e alterações sugeridas pela Comissão Julgadora durante a defesa da versão original do trabalho, realizada em 15/03/2017. Uma cópia da versão original está disponível no Instituto de Matemática e Estatística da Universidade de São Paulo.

Comissão Julgadora:

- Prof. Dr. André Fujita (orientador) - IME-USP

- Prof ${ }^{\mathrm{a}}$. Dr ${ }^{\mathrm{a}}$. Andrea Jackowski - Unifesp

- Prof. Dr. Edgard Morya - IINN-ELS 


\section{Agradecimentos}

Agradeço primeiramente à Universidade de São Paulo e ao Instituto de Matemática e Estatística por disponibilizarem e me aceitarem neste programa de mestrado, à CAPES pela bolsa que permitiu que eu me dedicasse integralmente aos estudos e ao meu orientador André Fujita por ter me aceitado como aluna e ter dedicado até várias horas por dia para me aconselhar. Agradeço também a meus pais que me permitiram deixar meu emprego estável e seguir meu sonho na pesquisa, mesmo sabendo que isso traria algumas dificuldades para nossa família.

Agradeço a todos os meus companheiros de laboratório, em especial ao Maciel cujo auxílio foi fundamental para execução deste trabalho, me fornecendo dados, material de estudo e sempre disposto a tirar minhas dúvidas. Também agradeço muito à Suzana que esteve sempre pronta a me ajudar com qualquer dúvida sobre o programa ou disciplina. Também foram muito atenciosos ao me auxiliar com dúvidas deste trabalho Grover e Adèle, alunos do nosso grupo de pesquisa. Agradeço ao Jorge por sua amizade e assistência com máquinas no laboratório. Agradeço Fernando, Anderson, Waldir, Gustavo, Paulo, Gabriela, Jaqueline, Vinícius, Leissi, Juan, Eric, Lucy, Caio e Igor pela companhia nos horários de trabalho, conversas filosóficas no café e conselhos em geral sobre a vida e carreira acadêmica.

Agradeço a todos os funcionários do IME-USP que de alguma forma contribuem para o funcionamento desta instituição. Em especial agradeço à Lucileide que foi sempre muito gentil e atenciosa para me auxiliar com todas as questões burocráticas do mestrado e ao Geraldo da portaria que se tornou um amigo querido.

Agradeço aos meus amigos Paula, Lucas, Paim, Pedro e Douglas pelos momentos que me ajudaram a relaxar, quando me deram força para continuar me esforçando, quando acreditaram em mim antes que eu mesma acreditasse e quando compreenderam que eu estava muito ocupada ou muito cansada para comparecer à algum evento. Os momentos de descontração foram fundamentais para me manter saudável e focada em minhas atividades acadêmicas. Agradeço em especial ao Carlos que me ajudou muito a manter minha dedicação nos últimos 
meses deste trabalho, e a não entrar em pânico, sempre me motivando a continuar. Agradeço também meu amigo Sandro que mesmo longe me apoiou a tomar a decisão de ingressar no mestrado e ao meu amigo Bakil que me disponibilizou até mesmo sua casa para que eu pudesse comparecer à algumas atividades acadêmicas.

Agradeço aos meus professores do ICMC-USP Simões, Renata, Mello e João Batista que me ajudaram a tomar esta importante decisão na minha vida de deixar o mercado de trabalho e voltar a estudar gastando até várias horas em conversas comigo por Skype neste momento que eu tanto precisei. Sou muito grata por todo o carinho que tiveram comigo.

Aos meus professores do ensino fundamental Reginaldo, Eduardo e José Ricardo que construíram grande parte do meu caráter e minha moral além de construírem minha confiança de que eu poderia conquistar todos os meus sonhos com meu esforço. E à minha professora do ensino médio Cristina que foi a primeira pessoa a acreditar que eu poderia entrar em uma universidade pública em um meio escolar onde isso estava tão distante da nossa realidade.

Agradeço principalmente ao grupo acolhe autismo que surgiu em minha vida em um dia que saí para buscar inspiração para este trabalho e de fato me inspirou e me acolheu. Graças à esse encontro do acaso eu pude perceber que meu trabalho não se resume à números, cálculos e métodos em um computador, que estes números são pessoas de verdade que tem histórias, que tem famílias, que tem problemas e preocupações maiores do que os gráficos podem mostrar. Pude ver que a motivação para este trabalho não seria simplesmente a obtenção de um título, mas uma tentativa de fazer alguma diferença, mesmo que mínima, na vida dessas pessoas. Agradeço Ana Lúcia Félix por ter fundado esse grupo lindo e ter me acolhido com tanto carinho. Agradeço imensamente à Ana Paula Chacur que me recebeu em sua casa, permitiu que eu conhecesse seus dois filhos autistas, dividiu comigo sua experiência e toda a luta que enfrenta até hoje, uma experiência que nenhum livro ou artigo poderia me fornecer. Tenho muito orgulho de todas essas mães que lutam pelos direitos de seus filhos e tenho certeza de que levarei esta luta comigo em todos os meus trabalhos futuros.

Dedico este trabalho à Helena, uma menina linda, amorosa e carinhosa, autista parcialmente verbal com hipoplasia do verme cerebelar. 


\section{Resumo}

RAMOS, T. C. Investigação de Alterações em Conectividades Funcionais CórticoCerebelares no Transtorno do Espectro Autista. 2017. Dissertação (Mestrado) - Instituto de Matemática e Estatística, Universidade de São Paulo, São Paulo, 2017.

Ainda pouco se sabe sobre as causas do transtorno do espectro autista (TEA) e seus efeitos na funcionalidade cerebral, porém, diversas pesquisas apontam que a condição esteja relacionada à uma conectividade diferenciada entre regiões do cérebro. A conectividade córtico-cerebelar tem sido tema de pesquisas nas últimas décadas em decorrência de novos achados que indicam que esta conectividade está relacionada ao aprendizado e refinamento de diversas funcionalidades do córtex. Acredita-se que uma falha na conectividade córticocerebelar poderia estar relacionada à falhas em funções sensorimotoras, cognitivas e emocionais. A investigação de regiões cuja conectividade córtico-cerebelar está alterada no TEA contribui para uma melhor compreensão deste transtorno. Assim, o objetivo deste trabalho é identificar regiões do cérebro cuja conectividade funcional com o cerebelo seja diferente entre indivíduos com desenvolvimento típico (DT) e diagnosticados com TEA. Para isto, utilizamos imagens de ressonância magnética funcional (fMRI) de 708 indivíduos em estado de repouso (432 DT e 276 TEA) com idades entre 6 e 58 anos coletados pelo consórcio ABIDE. Os dados foram pré-processados e divididos conforme regiões anatômicas do cérebro que foram adotadas como regiões de interesse (ROIs). Para determinar a conectividade funcional de cada região do córtex com o cerebelo, aplicamos o método de análise de componentes principais (PCA) nas ROIs do cerebelo e utilizamos um modelo regressão linear para cada ROI do córtex, sendo a série temporal da ROI do córtex a variável resposta e as componentes principais (PCs) do cerebelo as variáveis preditoras. Em seguida, identificamos as regiões com conectividade funcional diferente entre indivíduos com DT e diagnosticados com TEA através de um modelo linear que inclui como covariáveis, idade, gênero e local de coleta do dado. Identificamos cinco regiões do córtex que apresentam reduzida conectividade 
funcional com o cerebelo nos indivíduos com TEA, sendo elas: (i) giro fusiforme direito, (ii) giro pós-central direito, (iii) giro temporal superior direito e (iv) giro temporal médio direito e (v) esquerdo. Todas as cinco regiões são parte do sistema sensorimotor, e estão relacionadas à funções ligadas à sintomas característicos do quadro de TEA, como: sensibilidade à estímulos sensoriais, dislexia, prosopagnosia (dificuldade para reconhecer faces), dificuldade de compreensão de linguagem e dificuldade de reconhecimento de emoções em faces. Nossos resultados mostram que existem regiões do sistema sensorimotor que apresentam conectividade funcional com o cerebelo atipicamente reduzida em TEA, como corroborado por estudos de imageamento com tarefa específica e como hipotetizado por estudos de conectividade estrutural. Nós acreditamos que a conectividade córtico-cerebelar reduzida dessas regiões esteja prejudicando o processamento e aprendizado de funções sensorimotoras, levando ao surgimento de sintomas típicos do TEA.

Palavras-chave: transtorno do espectro autista, fMRI, conectividade funcional, conectividade córtico-cerebelar. 


\section{Abstract}

\section{RAMOS, T. C. Investigation of Altered Cortico-Cerebellar Functional Connecti-}

ons on Autism Spectrum Disorder.2017. Dissertação (Mestrado) - Instituto de Matemática e Estatística, Universidade de São Paulo, São Paulo, 2017.

Little is known about the causes of autism spectrum disorder (ASD) and its effects on brain functions. Several researches point that it may be related to differentiated connections between brain regions. The cortico-cerebellar connectivity has been theme of researches over the last decade given the new discoveries suggesting that this connection is associated with learning and tuning of diverse brain functionalities. It is believed that cortico-cerebellar connectivity impairment may be related to impairments on sensorimotor, cognitive, and emotional functions. For a better understanding of the condition, we aim at identifying brain regions that present a impaired cortico-cerebellar connectivity between TD and ASD. Thus, our goal is to identify brain regions where the functional connectivity with the cerebellum is different between subjects with typical development (TD) and ASD. We used functional magnetic resonance images (fMRI) of 708 subjects under resting state protocol (432 TD and $276 \mathrm{ASD}$ ) with ages between 6 and 58 years old collected by the ABIDE Consortium. Data was pre-processed, splited in anatomical brain regions, which were adopted as regions of interest (ROIs). To establish the functional connectivity of each cortical ROI to the cerebellum, first we applied the principal component analysis (PCA) on cerebellar ROIs. Next, we used a linear regression model to each cortical ROI time series as response variable and the cerebellum principal components (PCs) as the predictive variables. After that, we identified regions of different connections between TD and ASD subjects applying a linear model including age, gender, and data collection site as covariables. We identified five cortical regions with reduced functional connectivity with cerebellum on the ASD subjects, namely: (i) right fusiform gyrus, (ii) right postcentral gyrus, (iii) right superior temporal gyrus, (iv) right middle temporal gyrus, and (v) left middle temporal gyrus. All five regions are part of 
the sensorimotor system, and contribute to functions typically associated with ASD, such as: sensitivity to external stimulus, dyslexia, prosopagnosia (difficulty to recognize faces), language comprehension impairments, and recognition of emotional expressions impairment. Our results show that there are brain regions with atypical cortico-cerebellar connectivity impairment on ASD, in accordance with results from previous studies of tactography and task driven fMRI. We believe that the decreased cortico-cerebellar connectivity of these regions are affecting the learning process of sensorimotor functionalities, leading to typical ASD symptoms.

Key-words: autism spectrum disorder, fMRI, functional conectivity, cortico-cerebellar conectivity. 


\section{Sumário}

Lista de Abreviaturas $\quad$ ix

Lista de Figuras $\quad$ x

1 Introdução 1

2 Transtorno do Espectro Autista 3

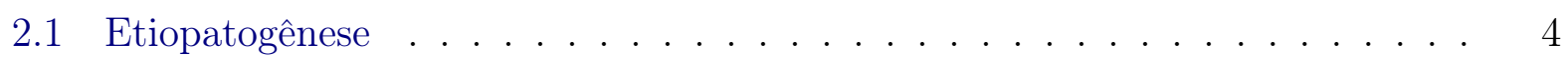

2.2 Diagnóstico . . . . . . . . . . . . . . . . . . . . . . 5

$\begin{array}{lll}3 & \text { Cerebelo } & 7\end{array}$

3.1 História . . . . . . . . . . . . . . . . . . . . . . . . . . 7

3.2 Divisões Anatômicas . . . . . . . . . . . . . . . . . 11

3.3 Células Purkinje . . . . . . . . . . . . . . . . . . . 12

3.4 Função . . . . . . . . . . . . . . . . . . . . . . . . . . . 13

3.5 Conectividade Córtico-Cerebelar . . . . . . . . . . . . . . . . . . 14

3.6 Cerebelo e TEA . . . . . . . . . . . . . . . . . 16

4 Ressonância Magnética Funcional $\quad 18$

4.1 Sinal BOLD . . . . . . . . . . . . . . . . . . . . . . 19

4.2 Séries Temporais . . . . . . . . . . . . . . . . 20

4.3 Pré-processamento . . . . . . . . . . . . . . . . . . . . 21

4.3.1 Correção da Temporização de Fatias . . . . . . . . . . . . . . . . . 22

4.3.2 Correção de Movimento . . . . . . . . . . . . . . . . . . 22

4.3.3 Pipeline de Pré-processamento . . . . . . . . . . . . . . 24

4.4 Atlas AAL . . . . . . . . . . . . . . . . . . . 25

4.5 Região de Interesse . . . . . . . . . . . . . . . . . . . . . . . . 26 
4.5.1 Definição das Regiões de Interesse . . . . . . . . . . . . . . . . 26

4.6 Conectividade Funcional . . . . . . . . . . . . . . . . . . 27

5 Aplicação em Dados Reais $\quad 29$

5.1 Banco de Dados . . . . . . . . . . . . . . . . . . . . 29

5.2 Seleção de Participantes . . . . . . . . . . . . . . . . . . . . 29

5.3 Regiões de Interesse . . . . . . . . . . . . . . . . . . . . . 30

5.4 Análise de Conectividade Funcional Córtico-Cerebelar . . . . . . . . . . . . . 30

5.4.1 Análise do Cerebelo . . . . . . . . . . . . . . . 34

6 Resultados 35

6.1 Análise de Conectividade Funcional Córtico-Cerebelar . . . . . . . . . . . . 35

6.2 Análise do Cerebelo . . . . . . . . . . . . . . . . . . . 35

7 Discussão $\quad 39$

7.1 Hipoconectividade córtico-cerebelar em TEA . . . . . . . . . . . . . . . . . 40

7.1 .1 Giro Fusiforme . . . . . . . . . . . . . . . 40

7.1.2 Giro Pós-central . . . . . . . . . . . . . . . . . . . . . 40

7.1.3 Giro Temporal Superior . . . . . . . . . . . . . . 40

7.1.4 Giro Temporal Médio . . . . . . . . . . . . . . . . 40

7.1.5 Conectividade Funcional Cerebelar . . . . . . . . . . . . . 41

7.2 Limitações do Estudo . . . . . . . . . . . . . . . . . . . . . . . . 41

$\begin{array}{ll}\text { Referências Bibliográficas } & 42\end{array}$ 


\section{Lista de Abreviaturas}

TEA Transtorno do Espectro Autista (Autism Spectrum Disorder)

DT Desenvolvimento Típico (Tipical Development)

fMRI Imagem de Ressonância Magnética Funcional (functional Magnetic Ressonance Imaging)

DTI Tactografia por Ressonância Magnética(Diffusion Tensor Imaging)

PET Tomografia por Emissão de Prótons(Positron Emission Tomography)

BOLD Dependente do Nível de Oxigênio no Sangue (Blood-Oxygen-Level Dependend)

ROI Região de Interesse (Regions of Interest) 


\section{Lista de Figuras}

3.1 Diagramas elaborados de somatotopia do cerebelo com base em mapeamento fisiológico. . . . . . . . . . . . . . . . . . . . . . . 9

3.2 Ativação do cerebelo em exame de PET durante atividade cognitiva. . . . . . 10

3.3 Reconstrução da superfície do cerebelo por MRI destacando os sulcos que são referência para a divisão em lóbulos do cerebelo. . . . . . . . . . . . . . . . . 11

3.4 Esquemático de um cerebelo "desenrolado" destacando a região do vérmis, hemisférios e mostrando a divisão em lobo anterior, lobo posterior e lobo floculonodular. . . . . . . . . . . . . . . . . . . . . . . . . . 12

3.5 Representação das regiões com conectividade funcional entre cerebelo e córtex. 14

3.6 Modelo de previsão de resposta sensorial. . . . . . . . . . . . . . . . . . 15

4.1 Esquemático de dilatação dos vasos sanguíneos conforme atividade neural. 19

4.2 Variação do sinal BOLD a partir de um estímulo externo. . . . . . . . . . . . 20

4.3 Exemplo de aquisição dos dados no tempo. . . . . . . . . . . . . . . . . . 21

4.4 Exemplo de problema que pode ocorrer ao coletar fatias em tempos diferentes. 23

4.5 Exemplo de problemas causados por movimentação da cabeça. . . . . . . . . 24

4.6 Etapas para o pré-processamento dos dados fMRI . . . . . . . . . . . . . . 25

4.7 Representação 3D do atlas AAL. . . . . . . . . . . . . . . . . . 26

4.8 Imagem dos experimentos realizados por Biswal. . . . . . . . . . . . . . . 28

5.1 Mapa de calor indicando porcentagem de leitura do cerebelo. . . . . . . . . . 31

6.1 Localização cortical das ROIs cuja diferença de conectividade funcional com o cerebelo é significativa entre os grupos DT e TEA. . . . . . . . . . . . 36

6.2 Boxplot comparando conectividade funcional entre os grupos DT e TEA. . . 37

6.3 Mapa de calor indicando a diferença na conectividade funcional das ROIs do cerebelo entre os grupos DT e TEA. . . . . . . . . . . . . . . . . 38 


\section{Capítulo 1}

\section{Introdução}

O transtorno do espectro autista (TEA) é considerada uma condição multifatorial, apresentando diversos sintomas e severidades. É um distúrbio caracterizado por dificuldades de interação social, atraso no desenvolvimento motor e cognitivo, dificuldade de comunicação, alta sensibilidade a estímulos externos, comportamentos repetitivos e irritabilidade. Também são observados sintomas gastrointestinais, seletividade alimentar, falta de demonstrações de afeto e agressividade [Ass13]. Vários termos já foram utilizados para diagnosticar as diferentes nuances do espectro autista, como por exemplo: autismo clássico, autismo de alto funcionamento, transtorno invasivo do desenvolvimento e síndrome de Asperger. Porém, a atualização de 2013 do manual de diagnóstico e estatística dos transtornos mentais 5a. edição (DSM-5) [Ass13], passou a diagnosticar todos os diferentes tipos de manifestação de autismo sob o nome de transtorno do espectro autista (TEA) acompanhado da severidade dos sintomas.

Os sintomas costumam aparecer antes dos três anos de idade. Muitos pais relatam um desenvolvimento mais atrasado em comparação com outros filhos de desenvolvimento típico já no primeiro ano de vida. É comum que a criança tenha atraso no desenvolvimento motor, e nas fases de desenvolvimento da primeira infância como se virar, sentar sozinha ou engatinhar [All88]. Existem relatos de crianças que apresentam desenvolvimento normal durante os primeiros anos de vida, incluindo desenvolvimento motor e de fala e posteriormente apresentam uma regressão brusca do desenvolvimento, perdendo principalmente o contato visual e a fala [Bol98]. Este caso costuma ser relatado na literatura como autismo regressivo ou autismo tardio.

Por muitos anos a comunidade científica manteve o consenso de que o cerebelo estava relacionado ao controle de atividades motoras desde que as primeiras pesquisas concluíram essa relação há cerca de 200 anos [Flo24, Swa14]. Apesar de alguns trabalhos da mesma época já apontarem que o cerebelo poderia estar ligado também a funções cognitivas [Com31], apenas nas últimas décadas a comunidade científica voltou a discutir o assunto. Um dos pontos fundamentais para isso foi o surgimento de novas técnicas de imagem como tomografia por emissão de pósitrons (PET) e ressonância magnética funcional (fMRI) que levantaram novas 
evidências sobre o envolvimento do cerebelo em funções além da motora $\left[\mathrm{PFP}^{+} 88, \mathrm{PFP}^{+} 89\right]$. Com base nas novas evidências a comunidade científica chegou a um novo consenso de que o cerebelo está também associado à atividades cognitivas [Nor14] e emocionais [Sch10] e que anomalias nesta estrutura estão ligadas à desordens psiquiátricas [Sch04, Sha14] e em especial ao autismo $\left[\mathrm{FAA}^{+} 12\right]$. As evidências de anomalias no cerebelo estarem ligadas ao autismo incluem estudos post-mortem que apontam anomalias em células Purkinje, incluindo tamanho e quantidade reduzidos $\left[\mathrm{FHR}^{+} 02\right.$, BK05, $\left.\mathrm{RFS}^{+} 86\right]$, hipoplasia do verme cerebelar $\left[\mathrm{CYCP}^{+} 88, \mathrm{HTM}^{+}\right.$95, $\mathrm{WSF}^{+}$09] e sinais de autismo em crianças prematuras com lesão cerebelar [LCS $\left.{ }^{+} 14\right]$.

Estudos tentam encontrar diferenças em regiões funcionais cerebrais no TEA, que seriam regiões responsáveis por execução de uma tarefa específica. Os resultados são bastante variados, o que motivou a hipótese de que os diversos fenótipos do TEA estejam relacionados à falhas em redes funcionais, que são diversas regiões funcionais conectadas para execução de uma tarefa mais complexa, em vez de falha em uma região funcional específica [MCK14, CDVBC $\left.{ }^{+} 16\right]$.

A teoria mais aceita hoje sobre o funcionamento da conectividade córtico-cerebelar se baseia na teoria já bastante discutida na literatura de que o cerebelo atua no refinamento, fluidez e aprendizagem de movimentos [Ram06, Gli92, KS03], estendendo o conceito para outras funções do córtex [Sch91, SS98, Sch04, Sch10, Ito06, Ito08]. A teoria se resume em o córtex gerar sinais de comandos a serem executados por outro sistema (por exemplo contração muscular para movimentação), o cerebelo recebe o sinal em paralelo ao sistema de destino e devolve ao córtex a previsão de resposta sensorial que ele prevê que esta ação terá com base em experiências anteriores. Este feedback sensorial antecipado permite que o córtex gere novos comandos sem precisar esperar a resposta efetiva mais lenta, dando mais fluidez às atividades (como a resposta muscular que permite o equilíbrio para andar de bicicleta, por exemplo). Quando a resposta sensorial efetiva chega ao cérebro, o cerebelo verifica se está de acordo com a resposta prevista e em caso negativo ocorre um processo de ajuste para refinar a previsão [Ito08, Ito06]. Uma publicação recente que resumiu as conclusões até o momento sobre a relação do circuito córtico-cerebelar com o TEA [CDVBC $\left.{ }^{+} 16\right]$ ressalta que a literatura até o momento ainda é bastante limitada neste assunto e há necessidade de mais pesquisas para compreensão do tema.

A teoria de conectividade córtico-cerebelar envolvida em funções motoras, cognitivas e emocionais e a hipótese do TEA estar relacionado à falhas de conectividade nos leva a crer que a investigação de regiões corticais em que a conectividade esteja diferenciada em TEA contribui para uma melhor compreensão deste transtorno. O principal objetivo deste trabalho é verificar se existe diferença de conectividade funcional entre regiões do córtex cerebral e o cerebelo no grupo de indivíduos com TEA em comparação com o grupo controle. Para isto, nós utilizamos exames de fMRI em estado de repouso coletados pelo consórcio Autism Brain Imaging Data Exchange (ABIDE) [DMYL $\left.{ }^{+} 14\right]$. 


\section{Capítulo 2}

\section{Transtorno do Espectro Autista}

É atribuído a Leo Kanner a primeira descrição do autismo como uma condição diferente das conhecidas até aquele momento, no qual o autismo era confundido com esquizofrenia e muitas vezes diagnosticado desta forma. Kanner em $1943\left[\mathrm{~K}^{+} 43\right]$ descreveu 11 casos de crianças que apresentavam grande preferência por ficar sozinhas, obsessão, uso restrito de palavras, ecolalia, estereotipias, pouca interação com outras pessoas e seletividade alimentar. A principal diferença apontada por Kanner entre o autismo e a esquizofrenia é que as crianças autistas apresentavam sinais do transtorno desde o nascimento, já na esquizofrenia existiam alguns anos de desenvolvimento típico antes do surgimento dos primeiros sintomas. Ainda neste trabalho ele relata melhora nos sintomas das crianças que por volta de 10 anos já apresentavam melhor uso das palavras, menor sensibilidade à estímulos externos e melhor aceitação de convivência social, porém ainda restrita. Em suas observações ele aponta que os pais das crianças estudadas apresentavam claros sinais de obsessão, especialmente pela descrição detalhada e precisa da rotina dos filhos e que não pareciam apresentar especial interesse em outras pessoas em sua vida cotidiana, acrescentando que seria desejável uma melhor investigação sobre a relação desse comportamento paterno com os sintomas da criança.

Hanz Asperger publicou trabalhos descrevendo o autismo no mesmo período que Kanner, mas ficou mais conhecido por sua descrição de um tipo de autismo mais leve que passou a ser chamado de síndrome de Asperger [Asp44, Asp77]. As principais diferenças são alta inteligência não-verbal, talentos específicos e vocabulário apropriado para a idade. Outros termos foram cunhados para descrever quadros específicos de autismo como: síndrome de Rett, transtorno desintegrativo da infância e transtornos invasivos do desenvolvimento sem outra especificação. Em 2013, a quinta revisão do Manual de diagnósticos e estatísticas de transtornos mentais (DSM-5) [Ass13] passou a unificar os termos no mesmo diagnóstico de transtorno do espectro autista, com a especificação da severidade do quadro por considerar que as síndromes não são claramente diferenciáveis.

Os dados diferem sobre a frequência de diagnóstico do TEA na população. Um estudo recente que unificou estatísticas de 11 locais de registro de saúde nos Estados Unidos em 
2012 estimou que 1 em 68 crianças com 8 anos de idade tinha diagnóstico de TEA. O estudo mostra também uma taxa maior de diagnósticos em meninos do que meninas, sendo 23,6 em 1000 meninos e 5,3 em 1000 meninas[Chr16].

O diagnóstico costuma ser feito na infância, e o diagnóstico precoce é de fundamental importância para o prognóstico, pois a intervenção com terapias para estímulo de desenvolvimento mostram significativa melhora nos sintomas cognitivos, sociais e motores [LED16]. Os sintomas costumam aparecer antes dos três anos de idade e muitos pais relatam atraso no desenvolvimento em comparação com outros filhos de desenvolvimento típico [All88]. Os mecanismos que levam ao desenvolvimento do TEA ainda são desconhecidos, havendo maiores evidências de relação genética $\left[\mathrm{CTM}^{+} 15\right]$, mas também alguns estudos apontando fatores como microflora gastrointestinal que pode ser afetada por fatores ambientais [FDS12].

\section{$2.1 \quad$ Etiopatogênese}

A causa do TEA não é conhecida para a grande maioria dos casos. Uma exceção é a síndrome de Rett, um tipo de severo de TEA, que esta ligada à uma mutação genética no cromossomo X $\left[\mathrm{AVdVW}^{+}\right.$99].

Apesar de mecanismos exatos que levam ao aparecimento e desenvolvimento dos sintomas não estarem bem estabelecidos, o fator genético é um dos que mais se destaca, pois apesar de ainda não ter sido possível determinar um conjunto de genes associados ao TEA, pesquisas com irmãos gêmeos idênticos tem mostrado forte influência genética, estimando uma herdabilidade de 56 a $95 \%\left[\mathrm{CTM}^{+} 15\right]$. Este estudo também aponta fraca influência de fatores ambientais compartilhados, como no casos de gêmeos dizigóticos. O estudo encontrou relação do diagnóstico de ambos os gêmeos com fatores ambientais compartilhados, mas aponta para um possível viés pelos questionários de diagnóstico de TEA (ADI-R) terem sido preenchidos pelo mesmo pai.

Fatores ambientais são constantemente investigados como possíveis causadores de autismo, porém as evidências não são conclusivas. Os maiores motivadores desta busca por fatores ambientais são os casos descritos na literatura como autismo regressivo, em que a criança apresenta desenvolvimento típico nos primeiros meses de vida e sofre uma brusca regressão de desenvolvimento, perdendo principalmente vocabulário, contato visual e se mostrando mais reclusa e agressiva [Bol98]. Devido aos avanços na área de microbiologia, estes casos tem motivado pesquisas que buscam relações entre TEA e microbiologia gastrointestinal, e os resultados apontam para uma possível relação com presença de bactérias do gênero clostridium no intestino [FMS ${ }^{+}$02, FDS12, KGBT14].

Pesquisas de alterações estruturais cerebrais não conseguiram até o momento determinar um biomarcador robusto, porém várias anomalias estruturais tem sido relacionadas ao TEA, em especial anomalias em relação ao cerebelo incluindo contagem e tamanho de células Purkinje diminuídos, hipoplasia do vérmis cerebelar e outras anomalias vermais. $\left[\mathrm{FHR}^{+} 02\right.$, 
$\mathrm{CYCP}^{+} 88, \mathrm{LCS}^{+} 14, \mathrm{WSF}^{+}$09] Outros fatores relacionados a anomalias cerebelares e TEA incluem: estresse oxidativo, disfunção mitocondrial, anomalias em vias de neurotransmissores GABA, glutamato, dopamina, serotonina, oxitocina e acetilcolina[HTM ${ }^{+}$95, $\mathrm{FAA}^{+}$12, Sha14,

Nor14]. Uma análise mais detalhada de fatores cerebelares relacionadas ao TEA se encontra na seção 3.6.

\subsection{Diagnóstico}

O diagnóstico do TEA é feito com base em observação dos sintomas e entrevistas com os pais da criança, além do preenchimento de alguns questionários como o Autism Diagnostic Interview (ADI) e Autism Diagnostic Observation Schedule (ADOS) que auxiliam o profissional no diagnóstico.

É possível observar sinais dos sintomas de TEA antes dos três anos de idade, sendo possível fazer o diagnóstico por volta dos 18 meses. É de fundamental importância a observação dos pais nesta fase para o diagnóstico precoce, pois iniciar intervenções terapêuticas ainda na primeira infância melhora o prognóstico, o desenvolvimento motor, social e o QI das crianças testadas em estudos comparativos [Rog96, DRM $\left.{ }^{+} 10\right]$. Os benefícios de intervenções antes dos quatro anos de idade são devidos à plasticidade neural que está mais ativa nos primeiros anos de vida, o que torna o diagnóstico nos primeiros anos de vida de fundamental importância.

Os sintomas observados mais facilmente nos primeiro ano de vida incluem não manter contato visual, não olhar ao ser chamado, não apontar coisas que quer, demonstrar mais interesse por objetos do que por pessoas, não interagir com brincadeiras dos pais e não retribuir sorrisos e risadas.

Apesar do DSM-5 não trazer informações sobre deficiência motora, atrasos motores também podem estar entre os primeiros sinais identificáveis para um diagnóstico precoce. Pesquisas apontam que uma maneira eficiente de identificar TEA em crianças pequenas é uma avaliação de habilidades motoras aos dois anos de idade [SPE ${ }^{+} 07, \mathrm{ZBL}^{+}$09].

Em 2013 o Manual de Diagnósticos e Estatísticas de Doenças Mentais passou por sua quinta revisão (DSM-5) [Ass13], trazendo uma nova estrutura de sintomas para a identificação e diagnóstico do TEA. Além disso, os sintomas que caracterizam déficits de comunicação foram separados em um novo diagnóstico de transtorno de comunicação social. A seguir listamos o critério de diagnóstico do TEA conforme especificado no DSM-5.

\section{Transtorno do Espectro Autista Critério e Diagnóstico}

A. Déficit de comunicação social e de interação social persistente em múltiplos contextos, com manifestação das seguintes formas:

1 Dificuldade na reciprocidade sócio-emocional, podendo se manifestar desde abordagens sociais não-convencionais até não querer dividir interesses, emoções ou 
afetos e dificuldade em iniciar e responder à interações sociais.

2 Dificuldades de reconhecer e utilizar comunicação não-verbal para interações sociais, desde dificuldade para integração de comunicação verbal e não-verbal; até anomalias no contato visual, dificuldades com linguagem corporal no entendimento e uso de gestos; até a ausência total de expressões faciais e comunicação não-verbal.

3 Dificuldade de desenvolver, manter ou sustentar relações, desde dificuldade de ajustar o comportamento conforme o ambiente social, até dificuldade de compartilhar atividades de imaginação com outros amigos, até total falta de interesse em outras pessoas.

B. Padrões restritos e repetitivos de interesses ou atividades manifestado por pelo menos dois dos seguintes itens:

1 Estereotipia ou repetição dos movimentos, no uso de objetos ou na fala (exemplos: estereotipias motoras, enfileirar brinquedos, rotacionar objetos, ecolalia, idiossincrasia).

2 Insistência em rotinas não flexíveis, padrões de rituais ou comportamento nãoverbal (exemplo: extrema rejeição à pequenas mudanças, dificuldade com transições, padrões de pensamento rígidos, rituais de saudação, necessidade de pegar sempre o mesmo caminho ou a mesma comida todos os dias).

3 Interesse bastante restrito anormal em intensidade ou foco (exemplo: forte ligação ou preocupação com objetos não-usuais, interesses excessivamente persistentes).

4 Reatividade exagerada ou diminuída à estímulos sensoriais ou interesse não-usual à aspectos sensoriais do ambiente (exemplo: indiferença aparente à dor ou temperatura, resposta adversa à sons ou texturas, cheirar ou tocar objetos de forma excessiva, fascínio visual por estímulos luminosos ou movimento).

C. Sintomas podem estar presentes desde a primeira infância, mas podem não se manifestar até que a demanda social ultrapasse os limites da capacidade, ou podem ser mascarados por estratégias aprendidas na vida mais tarde.

D. Os sintomas causam significante dificuldade social, ocupacional ou em outras importantes áreas de funcionamento.

E. Estes distúrbios não são melhor explicados por deficiência mental (transtorno do desenvolvimento intelectual) ou pelo atraso no desenvolvimento global. É comum que a deficiência intelectual e TEA ocorram em conjunto. Para fazer diagnósticos de comorbidade de TEA e deficiência intelectual, a comunicação social deve estar abaixo do esperado para o nível de desenvolvimento geral. 


\section{Capítulo 3}

\section{Cerebelo}

Desde o início das pesquisas sobre cerebelo até as últimas décadas, a literatura tem consistentemente relatado o cerebelo como sendo uma estrutura de função motora. Isto se deve aos primeiros resultados de pesquisas que eram feitos com animais e se baseavam em observar sequelas após lesões nas estruturas cerebrais [Flo24, SE52]. Esses estudos relataram deficiências motoras relacionadas á lesões nessa região o que se propagou na literatura como sendo a única função da região [Sch10].

Apenas mais recentemente, com o advento de novas tecnologias de imageamento como fMRI e tomografia por emissão de prótons (PET), que possibilitaram o estudo de cérebros durante a execução de tarefas, é que passamos a ter evidências de que o cerebelo poderia estar envolvido em outras tarefas além de tarefas motoras $\left[\mathrm{PFP}^{+} 88, \mathrm{PFP}^{+} 89\right]$.

Com base nas evidências de que o cerebelo poderia estar envolvido em mais funcionalidades que a motora, em 1998 Schmahmann e Sherman [SS98] publicaram uma pesquisa em que analisaram 20 pacientes que tiveram lesões cerebelares e avaliaram deficiências cognitivas e afetivas com testes controlados, o que mostrou que algumas lesões cerebelares poderiam levar à sequelas não-motoras.

Hoje, o envolvimento do cerebelo com outras funções e a relação de anomalias cerebelares com transtornos psiquiátricos tem sido tema de muitas pesquisas [Nor14, Sch10, Sha14, Buc13].

\subsection{História}

As primeiras evidências experimentais sobre a funcionalidade do cerebelo surgiram no início do século XIX baseadas em observações em animais. Em 1810, Luigi Rolando apontou que lesões cerebelares em animais resultaram em dificuldades motoras, mas não sensoriais ou intelectuais [GSV09], concluindo que o cerebelo seria responsável por gerar movimentos. Porém, em 1824 Pierre Flourens estudou pássaros submetidos a cerebelectomia e observou que os movimentos não foram totalmente perdidos, o que o levou à conclusões de que o cerebelo não seria responsável pela geração de movimentos, mas por sua coordenação [Flo24]. Ele 
também observou que parecia haver considerável recuperação das funções após os sintomas iniciais que seguiam uma lesão cerebelar.

Pouco após a publicação do trabalho de Flourens, Combette [Com31] publicou um relato da autópsia de uma menina de 11 anos com agênese cerebelar e que apresentava sintomas de deficiência intelectual. Sendo o primeiro registro que encontramos ligando o cerebelo à deficiência cognitiva. Apesar desse e outros relatos subsequentes ligando o cerebelo a outras funções além da motora, por muitos anos a literatura focou na funcionalidade motora do cerebelo, sempre dando destaque à essas sequelas após a lesão cerebelar [Sch10].

Posteriores estudos fisiológicos envolvendo estimulação cerebelar por eletrodos mostraram mudanças comportamentais especialmente quando estimulados o núcleo fastigial médio e o vérmis [BPM73, BMB74]. Importantes estudos fisiológicos foram feitos por Ray S. Snider e colegas que envolviam identificação de vias sensoriais ligadas ao cerebelo, estimulação sensorial e observação de respostas cerebelares com uso de eletrodos e estimulação de regiões do hemisfério cerebral e observação de resposta no cerebelo [SE52, SS44, SE51], como resultado destas pesquisas Snider elaborou um mapa sensorial 3.1 identificando dois lóbulos do vérmis (VI e VII) como sendo relacionados à funcionalidade auditiva e visual. O mais interessante deste mapa não são as partes identificadas, mas as partes que aparecem nos mapas sem nenhuma função atribuída, o que levantou questionamentos se essas regiões poderiam ter outra funcionalidade que não sensorimotora. Mais tarde, Snider demonstrou relações entre o vérmis cerebelar e parte do tronco cerebral associadas ao sistema límbico e aos hemisférios cerebrais, o circuito de Papez [SM76], o que o levou a sugerir que o cerebelo poderia estar relacionado à distúrbios psiquiátricos.

Por volta de 1960 surgiram importantes avanços no estudo do cerebelo, principalmente por publicações descrevendo circuitos neurais do córtex cerebelar, a função inibitória das células Purkinje [IYO64] e o conceito do cerebelo como uma máquina neuronal [Ito06].

Nos anos 1970, ocorreram importantes estudos envolvendo estimulação cerebelar, como o trabalho de Irving S. Cooper que relatou a estimulação por eletrodos no córtex cerebelar de pacientes epiléticos contribuindo para o controle de crises, mas também tendo melhora em características como na depressão, raiva e agressividade [CAR $\left.{ }^{+} 76\right]$.

Robert S. Dow e Giuseppe Moruzzi discutiram em seus trabalhos o envolvimento do cerebelo em funções não-motoras [DM58]. Posteriormente, Dow [Dow74] fez uma análise sobre algumas regiões do cerebelo terem evoluído em conjunto com áreas de associação temporais e pré-frontais e pela primeira vez foi sugerido que o cerebelo teria a mesma atuação que tem para a parte motora em outras funções do córtex. No início dos anos 1980, Dow em associação com Herietta e Alan Leiner reuniram uma série de evidências sugerindo que o cerebelo possui regiões ligadas à regiões de associação do córtex e chegaram a sugerir que métodos de imagem neural poderiam confirmar esta hipótese [LLD86, Lei10].

Também nos anos 1980, alguns trabalhos como de Margaret Bauman, Tom Kemper e Eric Courchesne apontaram diferenças anatômicas na região vermal e diferenças na contagem de células Purkinje em crianças autistas [BK85, $\left.\mathrm{CYCP}^{+} 88, \mathrm{~KB} 02, \mathrm{BK} 05\right]$. Estes achados, além 

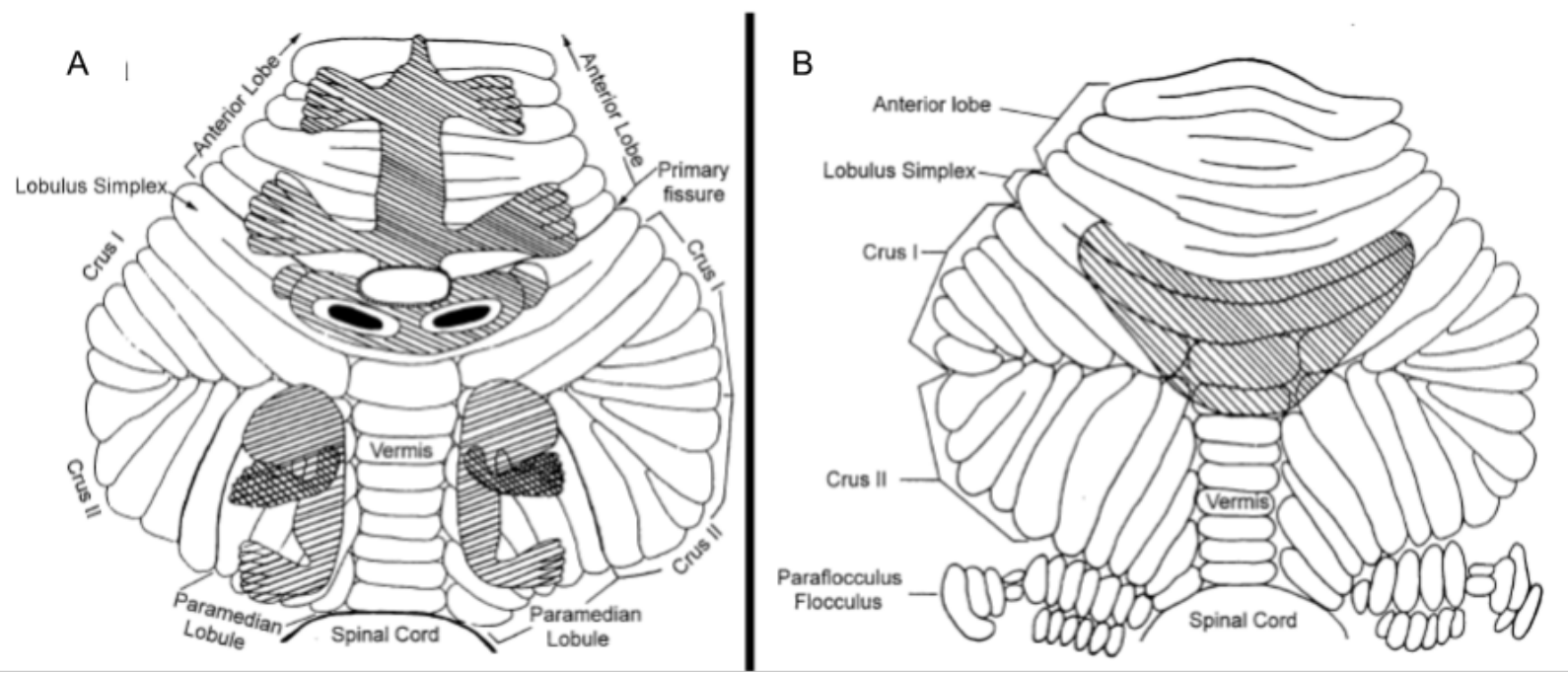

Figura 3.1: Diagramas elaborados por Snider e colegas da somatotopia do cerebelo com base em mapeamento fisiológico. (A) Homúnculo representando mapeamento sensorial no lobo anterior do cerebelo (lóbulos I-V) e se estendendo até o lóbulo simplex (VI). Existe uma segunda representação sensorial no lobo posterior que se concentra principalmente no lóbulo VIII. A região da Crus I e II e do vérmis quase não tem correspondência sensorial neste mapa. (B) Representação de correspondência de estímulos visuais e auditivos determinado por experiencia de exposição à luz e som destaca a região dos lóbulos VI e VIIA, principalmente na região do vérmis. Imagem original de Snider e Stowell [SS44] retirado e adaptado de Schmahmann [Sch10].

de corroborar com as ideias de que o cerebelo participa de funções cognitivas e emocionais e que pode estar relacionado à transtornos psiquiátricos, como proposto anteriormente por Snider, é particularmente interessante para este trabalho pois até onde nossa revisão bibliográfica pode encontrar, é a primeira vez que se associou diretamente o TEA com anomalias cerebelares.

No fim dos anos 1980, começo dos anos 1990 começaram a surgir técnicas de imagem cerebral como PET e fMRI que permitiram a observação de ativação cerebral durante a execução de tarefas. Apesar das técnicas serem limitadas por serem medidas de atividade indireta, gerando dúvidas sobre a origem do sinal observado, elas foram de fundamental importância para o estudo de regiões envolvidas em atividades específicas. Um dos trabalhos de destaque usando PET para observar a função do cerebelo foi o de Steve Petersen $\left[\mathrm{PFP}^{+} 88\right.$, $\mathrm{PFP}^{+}$89] que utilizou a técnica para observar o envolvimento do cerebelo em uma tarefa em que os participantes deveriam falar as palavras que estavam lendo, o que demandaria controle motor. Além de ler, em uma próxima etapa os participantes deveriam dizer um verbo relacionado à palavra que estavam vendo. Esta etapa de geração de palavras foi o que tornou este trabalho particularmente interessante para estudos do cerebelo, pois para esta tarefa foi observado uma forte atividade no hemisfério cerebelar direito, como apresentado na Figura 3.2. A resposta observada foi diferente da resposta motora esperada para o cerebelo, que deveria ser localizada principalmente no lobo anterior, o que levou os pesquisadores a sugerir que esta atividade cerebelar estava relacionada à atividade semântica ligada à tarefa.

Apesar de todas as evidências apontarem o envolvimento do cerebelo com funções não- 

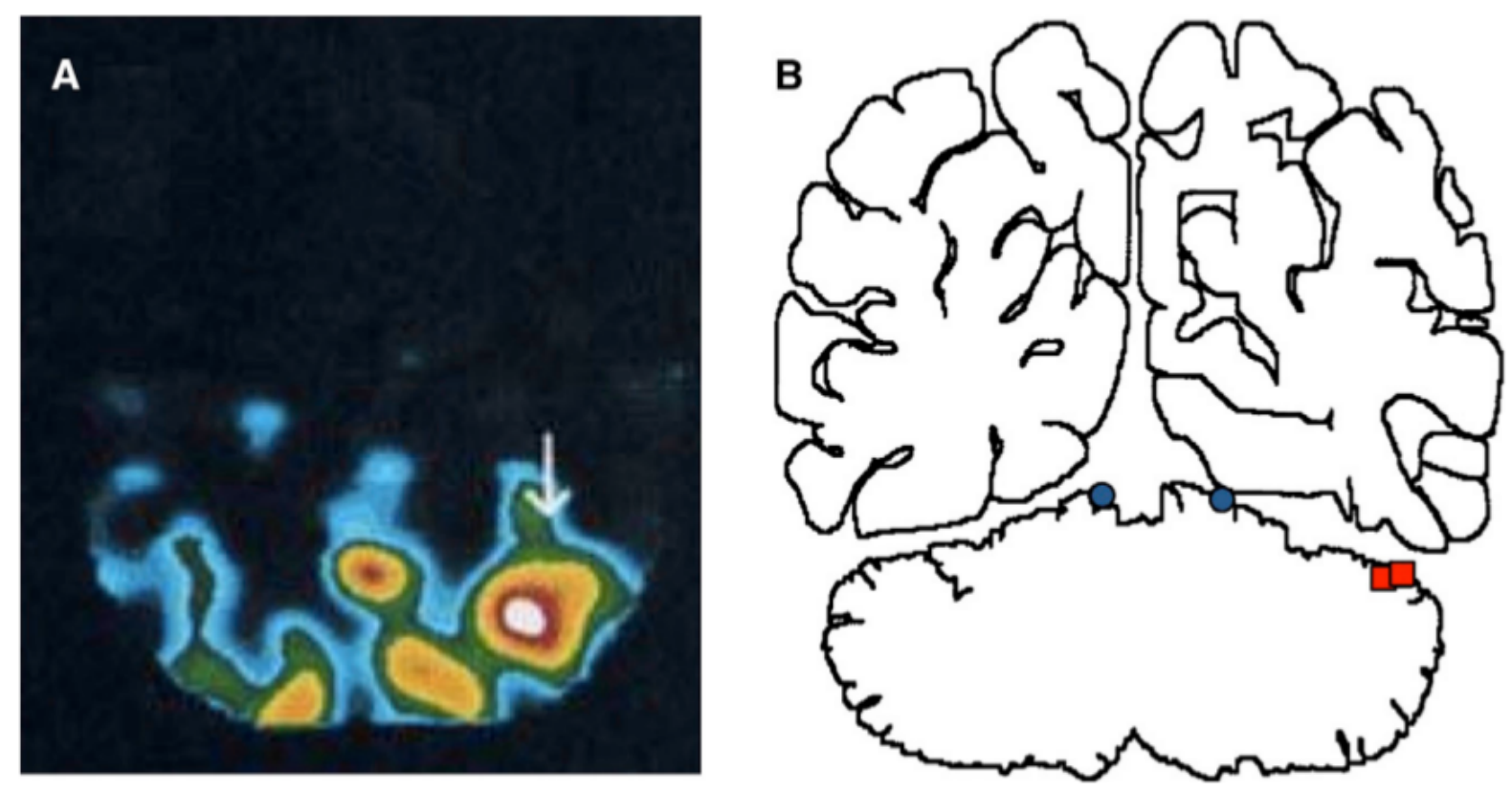

Figura 3.2: Ativação do cerebelo em exame de PET durante atividade cognitiva. (A) Corte coronal do cerebelo mostrando atividade intensa no hemisfério cerebelar direito durante atividade de associação de verbos à palavras apresentadas. (B) Diagrama mostrando regiãa de ativação cerebelar durante atividades com demandas motoras para leitura de palavras (círculos azuis) e regiões de ativação cerebelar durante atividade de associação de palavras (quadrados vermelhos). Reprodução da imagem de Petersen $\left[\mathrm{PFP}^{+}\right.$89] retirado e adaptado de Buckner [Buc13].

motoras, a maior parte da literatura médica se manteve descrevendo o cerebelo como tendo exclusivo envolvimento com funções motoras [Sch10, GSV09, Buc13]. Isto ocorreu principalmente pelo fato das conexões cerebelares com outras partes do cérebro serem feitas principalmente por circuitos polisinápticos. As técnicas existentes até aquele momento para determinar a conectividade neural não atravessava sinapses, o que não permitia determinar a conectividade através de circuitos polisinápticos. Apenas mais tarde com o desenvolvimento de técnicas de mapeamento neuronal utilizando vírus da raiva [KS00], que podia atravessar as sinapses, foi possível o mapeamento de conexões físicas entre o cerebelo e áreas de associação do córtex cerebral demonstrando que realmente havia uma via física que possibilitava o envolvimento do cerebelo em funções não-motoras [MS94, MS00, MS01].

Outro trabalho importante que reforçou a ideia de que o cerebelo não está envolvido exclusivamente com funções motoras foi de 2009 de Jeremy D. Schmahmman [SMV09] na qual ele aponta que, em uma pesquisa que pretende avaliar a possibilidade do cerebelo estar envolvido em funções não-motoras, a hipótese nula é que uma lesão em qualquer região do cerebelo irá provocar sintomas motores. Neste trabalho ele observou 39 pacientes vítimas de derrame localizado apenas na região do cerebelo e avaliou segundo uma escala de ataxia (do inglês Modified International Cooperative Ataxia Rating Scale MICARS). Ele separou os pacientes observados em grupos conforme a região da lesão e realizou testes de hipótese para avaliar se todos os grupos apresentavam ataxia e se a escala de ataxia diferia entre os grupos. As conclusões foram que se observava ataxia em pacientes que tiveram 
derrames no lobo anterior (lóbulos I-V), não se observava ataxia em pacientes que tiveram derrames nos lóbulos VII-X e que pacientes que tiveram derrame no lóbulo VI apresentavam ataxia modesta. Demonstrando que o cerebelo não poderia estar envolvido exclusivamente em funções motoras.

Hoje, o grande número de pesquisas usando técnicas de imagem para estudo de atividade neuronal reuniu fortes evidências de que o cerebelo está envolvido em atividades cognitivas $\left[\mathrm{BKC}^{+} 11, \mathrm{Buc}_{13}, \mathrm{OBT}^{+} 10\right]$. As técnicas de imagem também tem sido utilizadas para inferir a conectividade cerebral com base nas observações de que as flutuações espontâneas observadas em modo de repouso refletem a organização cerebral [BYHH95].

\subsection{Divisões Anatômicas}

O cerebelo é dividido anatomicamente em lóbulos com base em sulcos destacados na Figura 3.3. A parte central do cerebelo dividida verticalmente é chamada de vérmis e as regiões maiores laterais são chamadas de hemisférios como ilustrado na Figura 3.4.
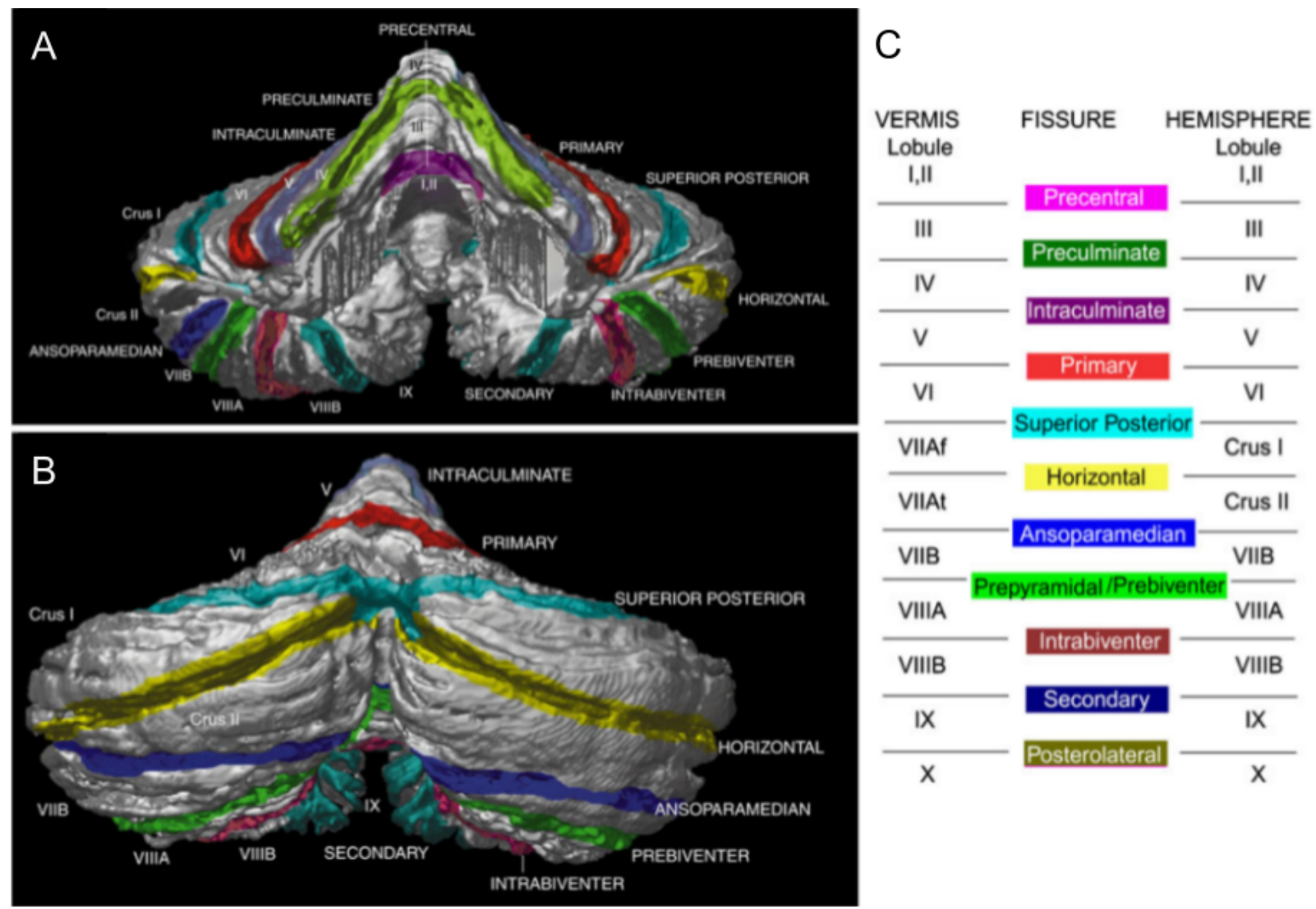

Figura 3.3: Reconstrução da superfície do cerebelo por MRI destacando os sulcos que são referência para a divisão em lóbulos do cerebelo. (A) Visão anterior do cerebelo. (B) Visão posterior do cerebelo. (C) Tabela identificando a separação dos lóbulos de acordo com os sulcos e mostra a relação entre a nomenclatura do lóbulo no vérmis e no hemisfério. Imagem original de Schmahmann [SDP $\left.{ }^{+} 00\right]$ retirado de Schmahmann [Sch10].

O sulco primário divide o cerebelo em lobo anterior e lobo posterior e o sulco posterolateral divide o lobo floculonodular. O lobo anterior é dividido em cinco lóbulos (I-V), o 
lobo posterior na região da vérmis é dividido em quatro lóbulos (VI-IX), sendo que o VII se divide em três lóbulos na região dos hemisférios (CrusI-II e VIIB) e o lóbulo VIII se divide em dois na região dos hemisférios (VIIIA e B), o lobo floculonodular é representado como lóbulo X.

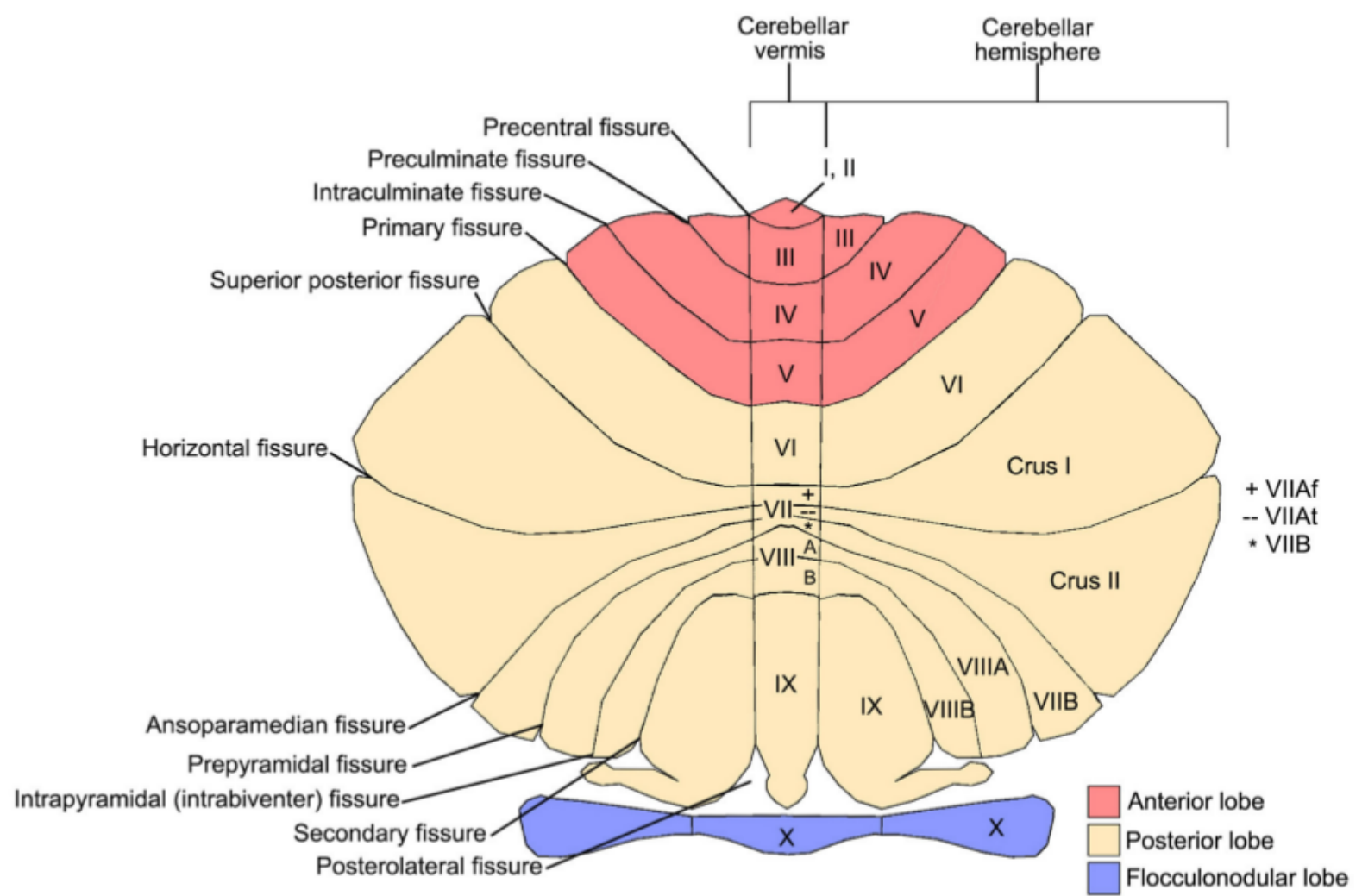

Figura 3.4: Esquemático de um cerebelo "desenrolado" destacando a região do vérmis, hemisférios e mostrando a divisão em lobo anterior, lobo posterior e lobo floculonodular. Imagem de autoria de Schmahmann retirado de D'Mello e Stoodley [DS15].

\subsection{Células Purkinje}

O cerebelo é composto de diversos tipos de células como: células estreladas, células em cesto, células Purkinje e células granulares. Nesta seção daremos destaque às células Purkinje por ser um tipo de célula constantemente associada ao TEA na literatura $\left[\mathrm{RFS}^{+} 86, \mathrm{FHR}^{+} 02\right.$, $\mathrm{BK}_{05}, \mathrm{BLD}^{+}$98].

Como citado anteriormente, por muito tempo a literatura se focou na funcionalidade motora do cerebelo, portanto, as pesquisas de células Purkinje se focaram em sua atuação na regulação da atividade motora e de aprendizado motor, porém, é possível que elas estejam envolvidas também em funções cognitivas [Ito02]. São as únicas células que emitem sinais do córtex cerebelar e recebem sinais de até centenas de milhares de células. São células de função inibitória que atuam liberando neurotransmissores GABA. Ito sugere que as células Purkinje possuem importante papel no loop de aprendizado através da informação recebida 
pelas vias aferentes [Ito02].

\subsection{Função}

A investigação de localização de funcionalidades relacionadas ao cerebelo tem integrado diversos recursos de pesquisa como morfologia (anatomia comparativa, embriologia), fisiologia (estudos com estímulos em regiões específicas), patologia (casos clínicos) e estudos de neuroimagem. As pesquisas se focaram por muito tempo quase exclusivamente na investigação da relação do cerebelo com funções sensorimotoras, por tanto, a localização dessas funcionalidades é mais bem definida.

Como citado na seção 3.1, baseado em pesquisas de Snider e colegas entre 1940 e 1950 temos um mapa de identificação de regiões sensorimotoras no cerebelo apresentado em 3.1 que identifica estas funcionalidades localizadas principalmente na região do lobo anterior e parte do lobo posterior, principalmente na região do vérmis IV e na região dos hemisférios VIII [SE52]. Apesar deste mapeamento de funcionalidade ter sido realizado em gatos, trabalhos mais recentes tem confirmado esses achados [SS10] e a rede sensorimotora córtex-cerebelar é considerada bem estabelecida, mantendo o conceito de que estas funcionalidades estão mais localizadas no lobo anterior e apenas parte do lobo posterior e deixando grande parte do lobo posterior sem função definida.

A localização de outras funcionalidades no cerebelo ainda está sendo definida e vários estudos tem tentado responder esta questão [Buc13]. Selecionando estudos bem definidos de funcionalidades sensorimotoras, de memória de trabalho, de formação de palavras e de ativação límbica, Stoodley e Schmahmman confirmaram as regiões de ativação para funcionalidade sensorimotora como sendo o lobo anterior, lóbulo VI e lóbulo VIIIB, já as atividades cognitivas e límbicas tendo ativação do lobo posterior. Esses achados foram confirmados posteriormente em um estudo de fMRI de um grupo de nove indivíduos [SVS12].

Estudos de mapeamento funcional do cerebelo com base em fMRI tem confirmado a separação do cerebelo em regiões sensorimotoras e regiões cognitivas e límbicas [SVS12, $\mathrm{OBT}^{+}$10, Buc13]. Os estudos não apresentam separações específicas entre funcionalidades do vérmis e dos hemisférios, indicando uma possível organização funcional mais horizontal do que vertical, como pode ser observado na Figura 3.5. Buckner $\left[\mathrm{BKC}^{+} 11\right]$ também indica uma maior conectividade funcional do cerebelo com regiões do córtex da rede de associação, indicadas na Figura 3.5 pelas cores laranja e vermelho.

As evidências atuais mostram que o cerebelo possui ativação em atividades não relacionadas a processamento sensorimotor, mas pouco se sabe sobre como o cerebelo contribui para o processamento dessas funcionalidades. As hipóteses mais aceitas hoje sobre o que o cerebelo faz se baseiam na ideia de que a mesma contribuição que ele exerce para a função sensorimotora, é aplicada para todas as outras funções [Ito06, Sch91]. O mecanismo de atuação do cerebelo com relação à funções do córtex é discutido em mais detalhes na seção 

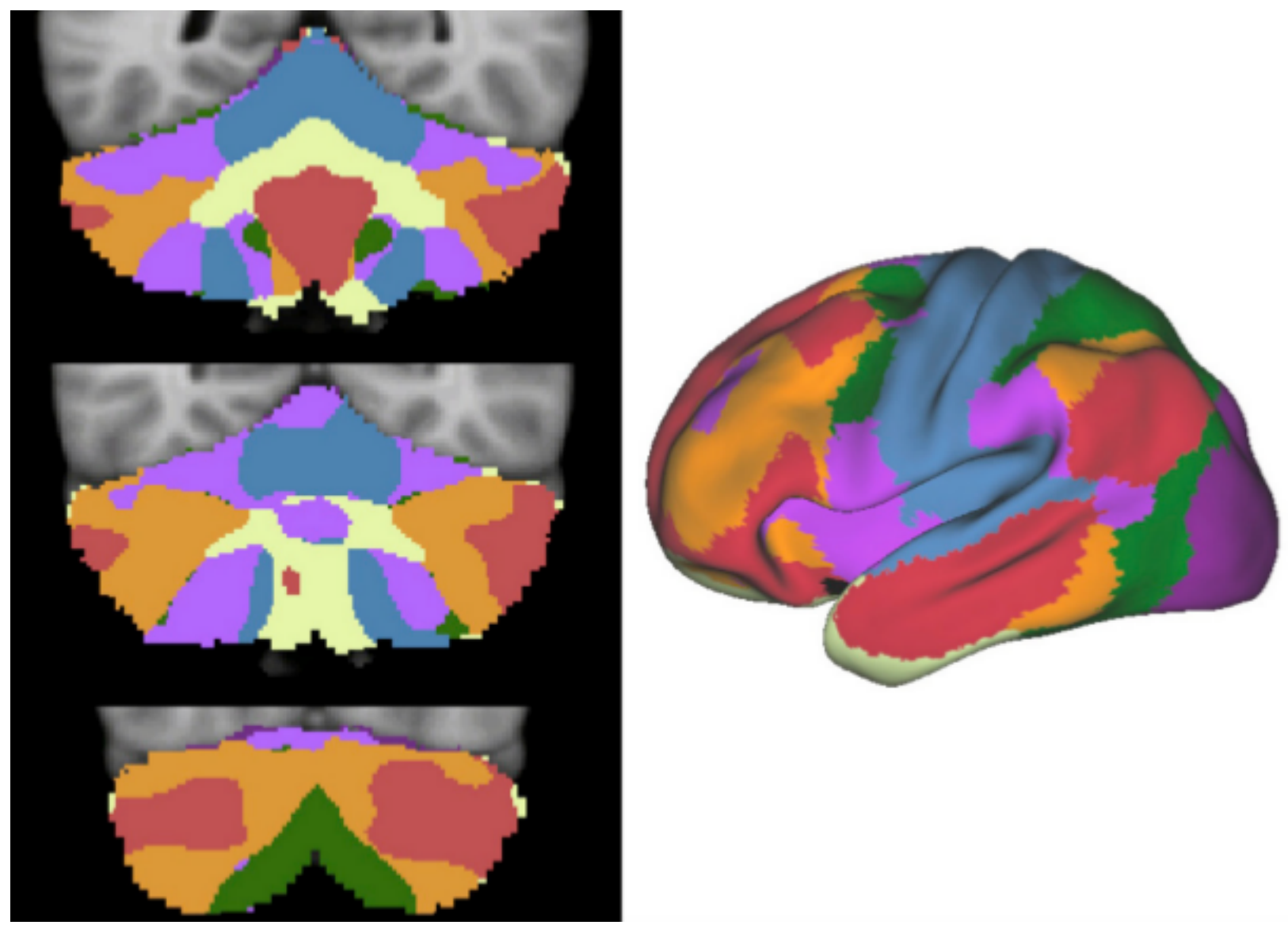

Figura 3.5: Representação das regiões com conectividade funcional entre cerebelo e córtex. A região sensorimotora está representada em azul e ocupa regiões do lobo anterior e posterior. Os hemisférios do lobo posterior estão em maior parte relacionados com redes de associação do córtex representadas pelas cores laranja e vermelho. Imagem retirada de Buckner [Buc13].

4.6. Apesar do mecanismo de atuação do cerebelo ainda não ser bem conhecido, as evidências de ativação cerebelar na ausência de movimentação mostram separação funcional como observado no córtex e são uma mudança de paradigma em relação à antiga ideia de que o cerebelo estivesse envolvido somente em tarefas motoras.

\subsection{Conectividade Córtico-Cerebelar}

Como citado na seção 3.1, as técnicas de avaliação de conectividade cerebral só permitiram a determinação da conectividade do cerebelo com áreas de associação quando introduzida a técnica de mapeamento viral [KS00]. Até então, só se podia verificar que o cerebelo apresentava conectividade com a medula espinhal, o que reforçava a ideia de função motora do cerebelo [Sch10]. Com a introdução de novas técnicas de mapeamento de sinapses e técnicas de neuroimagem que permitiam a observação de áreas de ativação como o PET e o fMRI, foi possível determinar que existe conectividade do cerebelo com outras áreas do córtex, em especial, áreas não associadas à função motora, como o lobo frontal [KS03, Ram06].

As evidências atuais indicam que o cerebelo é composto de múltiplos módulos indepen- 
dentes, em que cada pequeno módulo é parte de um loop que envia e recebe informações de uma área do córtex cerebral específica. Como exemplo, temos a ligação córtico-pontocerebelar em que o cerebelo retorna projeções para o córtex através do tálamo [Ram06].

Uma das teorias mais aceitas atualmente sobre a funcionalidade da conectividade córticocerebelar através do loop é a teoria de feedback interno [Gli92]. Neste modelo o cerebelo atua como um modelo de previsão de resposta (foward model). Ito exemplifica o funcionamento da teoria na execução de movimentos já aprendidos anteriormente como representado na Figura 3.6 [Ito05]. A instrução vinda de regiões de planejamento do movimento como a áreas motora suplementar (SMA), a áreas pré-motora e o giro anterior cingulado (ACG) é enviada para o córtex motor primário que gera e envia o sinal do movimento a ser realizado para o aparato motor (músculos). Paralelamente, o córtex motor envia os sinais para o cerebelo, que envia de volta a resposta sensorial prevista através do tálamo. O sinal previsto pelo cerebelo é enviado ao córtex motor antes que uma resposta sensorial de fato seja recebida em decorrência do movimento realizado. Se a previsão estiver próxima da correta, regiões do córtex cerebral podem controlar o aparato motor sem precisar esperar a resposta sensorial efetiva, que seria mais lenta que a resposta do cerebelo, o que possibilita a execução de movimentos com maior fluidez e velocidade. Para garantir que a previsão esteja sempre próxima do resultado real, um sistema de aprendizado cerebelar (feedback externo) atua recebendo a resposta sensorial, comparando com a resposta prevista e regula a resposta das células Purkinje para se aproximar da resposta correta [Ito05].

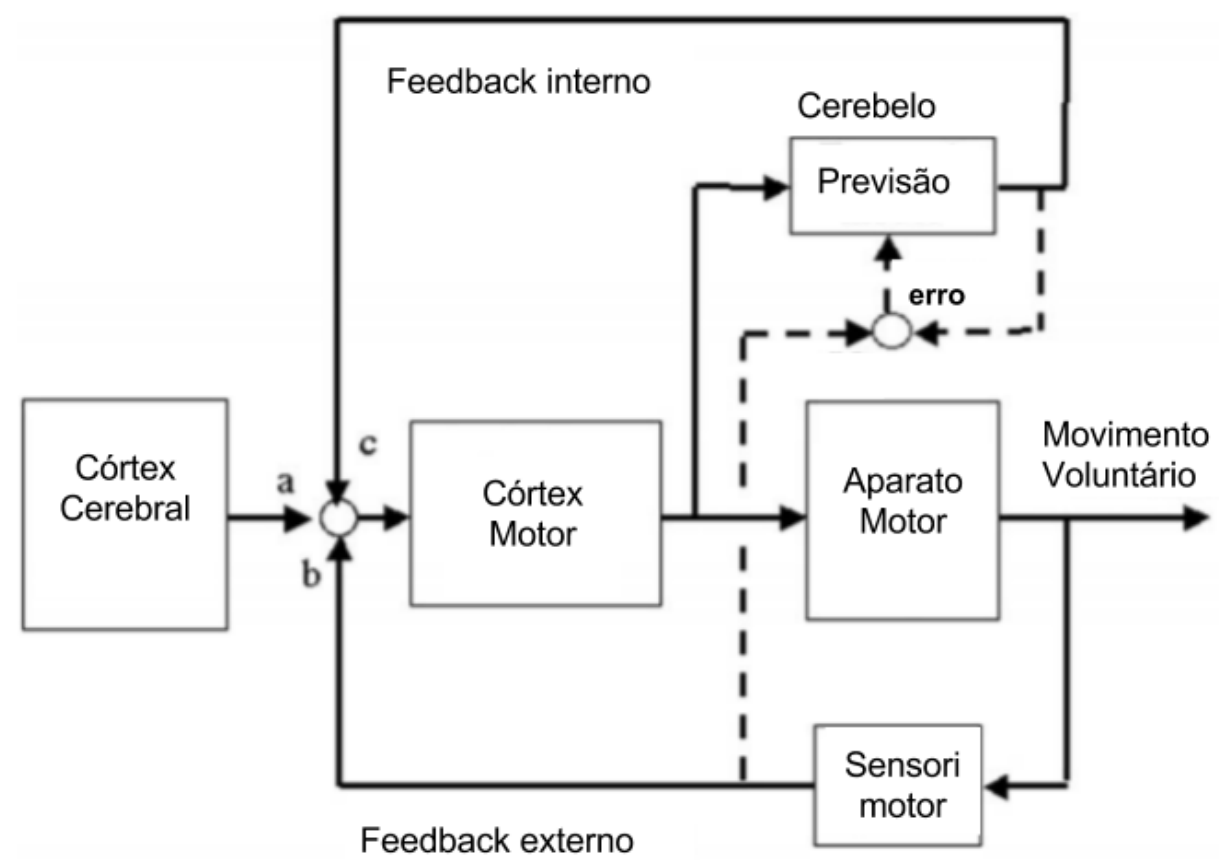

Figura 3.6: Modelo de previsão de resposta sensorial. (a) É a instrução da movimentação vindo de áreas de planejamento motor. O córtex motor processa a instrução e o sinal segue em paralelo para o aparato motor e para o cerebelo. A resposta sensorial efetiva (b) é sobreposta pela resposta prevista pelo cerebelo (c). Imagem adaptada de Ito [Ito05]

Este mecanismo de aprendizado poderia estar relacionado a outras funções não-motoras, 
já que o cerebelo estaria também envolvido em funções cognitivas e afetivas, como proposto por Schmahmann em diversos trabalhos e observado em pacientes com lesões cerebelares dando origem à teoria de dismetria de pensamento [Sch91, Sch98, SS98, Sch04, Sch10]. Desta forma, uma falha na conectividade córtico-cerebelar prejudicaria o funcionamento deste mecanismo e consequentemente o aprendizado e execução de diversas funcionalidades motoras, cognitivas e emocionais. Por este motivo, passou-se a considerar a possibilidade do TEA estar relacionado à uma diferença de conectividade córtico-cerebelar que afetaria essas funções, comumente relatadas como sendo afetadas em quadros de TEA [CDVBC ${ }^{+} 16$, $\left.\mathrm{MSK}^{+} 11, \mathrm{KUK}^{+} 14\right]$.

\subsection{Cerebelo e TEA}

Existem diversas evidências que apontam anormalidades cerebelares estruturais e funcionais em TEA. Muitos achados ainda necessitam maior investigação. Nesta seção apontamos algumas evidências da relação entre cerebelo e TEA citadas na literatura.

Um dos achados mais consistentes até o momento em relação à anormalidades cerebrais e TEA envolve o cerebelo. Quase todos os estudos post-mortem de cérebros de indivíduos diagnosticados com TEA tem mostrado quantidade de células Purkinje significativamente reduzidas, independente de idade, sexo e habilidades cognitivas. $\left[\mathrm{RFS}^{+} 86, \mathrm{BBB}^{+} 15, \mathrm{BK} 85\right.$, BK05, FHR ${ }^{+}$02]. Apesar de vários estudos detalhados, ainda não há evidências de uma menor quantidade destas células na região do vérmis cerebelar, não possibilitando uma explicação celular para as anomalias vermais consistentemente relatadas por estudos de imagem $\left[\mathrm{CYCP}^{+} 88, \mathrm{CST}^{+}\right.$94]. Estudos apontam que as células Purkinje são formadas normalmente em crianças com TEA e morrem após migrarem para o local apropriado ainda no período gestacional, o que caracteriza uma condição pré-natal. Apesar disso, várias evidências relacionando contagem de neurônios, tamanho do cérebro e espessura do córtex em TEA apontam para um processo neuropatológico que continua após o nascimento [FAA $\left.{ }^{+} 12\right]$.

Observações de pacientes que sofreram lesão cerebelar envolvendo o lobo posterior do vérmis cerebelar foram associados à deficiências cognitivas sutis, deficiência em funções executivas, deficiências de comunicação expressivas, dificuldade de envolvimento afetivo ou desinibição, todos sintomas observados em casos de TEA [SS98]. Estudos post-mortem apontam hipoplasia do vérmis cerebelar nos lóbulos VI-VII $\left[\mathrm{CYCP}^{+} 88, \mathrm{CST}^{+} 94\right]$, porém, estudos de imagem sugerem hipoplasia em outras regiões do vérmis como no lobo anterior (lóbulos I-V) e lóbulos VIII-X [SSGJA09]. Devido aos achados variados, a teoria de hipoplasia vermal em regiões específicas foi modificada e passou a ser mais aceita atualmente a ideia de que indivíduos com TEA apresentam em sua maioria hipoplasia em alguns lóbulos e um pequeno grupo apresenta hiperplasia vermal $\left[\mathrm{CST}^{+}\right.$94]. A hipoplasia vermal tem sido relacionada à disfunções cognitivas em vários outros transtornos infantis além do TEA e apesar do mecanismo não ser conhecido e os achados serem heterogêneos, é uma característica de 
anormalidade anatômica bastante citada na literatura de $\left.\mathrm{TEA}_{[\mathrm{FAA}}{ }^{+} 12, \mathrm{BBB}^{+} 15\right]$.

Estudos de síndromes genéticas que costumam ter um diagnóstico conjunto de TEA dão claras evidências da relação do TEA e anormalidades cerebelares. Por exemplo, a síndrome do X frágil (do inglês Fragile X Syndrome - FXS) é uma das causas genéticas herdadas mais comuns de deficiência intelectual e cerca de $30 \%$ dos pacientes são também diagnosticados com TEA. Apesar desta síndrome afetar diversas regiões cerebrais, estudos de imagem apontam anormalidades cerebelares nos lóbulos VI e VII do vérmis em pacientes de FXS com TEA que não estão presentes em pacientes de FXS sem TEA [FAA $\left.{ }^{+} 12\right]$. Outro exemplo é a esclerose tuberosa que tem cerca de $40 \%$ de pacientes co-diagnosticados com TEA dentre os quais, os que apresentam lesões cerebelares tendo sintomas mais severos de TEA do que os que tem lesões apenas em outras áreas cerebrais $\left[\mathrm{EBC}^{+} 06\right]$. A síndrome de Joubert, que é caracterizada por uma hipoplasia do vérmis cerebelar significativa tem até $40 \%$ dos pacientes também diagnosticados com TEA $\left[\mathrm{FAA}^{+} 12\right]$. 


\section{Capítulo 4}

\section{Ressonância Magnética Funcional}

A técnica de ressonância magnética (MRI) teve importante contribuição para a ciência e medicina ao permitir a observação anatômica de diversos tecidos in vivo, permitindo exames não invasivos. Porém, a informação obtida com o MRI era apenas sobre forma dos tecidos e características físico-químicas (ex.: matéria branca ou matéria cinza cerebral). As técnicas para observação do funcionamento de tecidos, em especial do cérebro, necessitavam da utilização de contraste, muitas vezes radioativo, como no caso do PET, o que poderia ser prejudicial à saúde do paciente impossibilitando uma alta frequência de exames deste tipo. Em 1990, Seiji Ogawa e colegas demonstraram que seria possível adaptar o MRI para observar atividades fisiológicas no cérebro [OLKT90], o que passou a ser uma técnica relativamente barata e não invasiva para estudar o funcionamento do cérebro.

Os trabalhos de Ogawa et al. se basearam principalmente em dois conceitos: o primeiro é o conceito de que o fluxo de sangue aumenta de forma significativa e localizada conforme o metabolismo cerebral aumenta em áreas de atividade [RS90]; e o segundo é o conceito demonstrado por Linus Pauling e Charles Coryell em 1936 de que a molécula de hemoglobina, componente sanguíneo que atua no transporte de oxigênio para as células do corpo, tem comportamento magnético diferenciado em sua forma oxigenada e não oxigenada [PC36]. Ogawa e colegas demonstraram como estas propriedades poderiam ser detectadas utilizando a técnica de MRI [OLKT90]

Ainda em 1990, Ogawa demonstrou que a atividade metabólica cerebral causava mudanças significativas na quantidade de hemoglobina oxigenada e desoxigenada do cérebro, sendo possível utilizar a técnica para observar áreas de atividade cerebral em ratos [OLNG90]. Dois anos depois começaram a surgir trabalhos mostrando que a técnica poderia ser aplicada também em humanos e que era possível observar atividade cerebral localizada desencadeada por estímulos externos $\left[\mathrm{OTM}^{+} 92\right]$.

A técnica passou a ser conhecida como MRI funcional (fMRI) e passou a ser uma técnica fundamental para o campo da neurociência cognitiva. Hoje a técnica tem permitido um melhor mapeamento de localidades funcionais no cérebro e compreensão de áreas que atuam em conjunto para desempenho de tarefas mais complexas, inferindo uma conectividade funcional 
do cérebro.

\subsection{Sinal BOLD}

O neurônio é um tipo de célula que não possui reservas de energia, e por tanto, ao aumentar sua atividade, necessitam de um maior suprimento de energia por meio do sangue. Em 1945 Seymour Kety e Carl Schmidt [KS45] demonstraram que quando o neurônio utiliza mais oxigênio, sinais químicos são disparados causando a dilatação de vasos da região. Essa dilatação dos vasos causa um aumento do fluxo sanguíneo da região como representado na Figura 4.1. Este aumento no fluxo sanguíneo é chamado de resposta hemodinâmica.
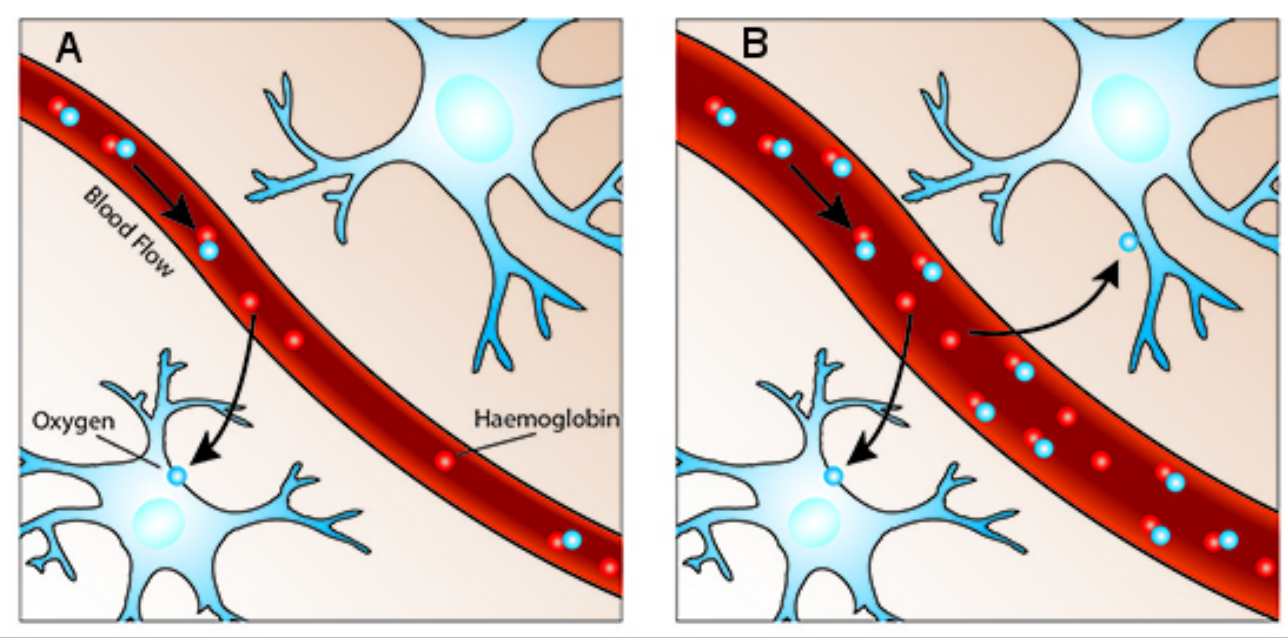

Figura 4.1: Esquemático de dilatação dos vasos sanguíneos conforme atividade neural. (A) Neurônios com baixa atividade neural. (B) Neurônios com maior atividade neural causando uma dilatação dos vasos sanguineos. Imagem adaptada de http://ndcn.ox.ac.uk/divisions/fmrib/what-is-fmri/ introduction-to-fmri.

O processo de MRI se baseia em utilizar um campo magnético forte para orientar prótons de moléculas de água em uma direção determinada pelo campo. Os prótons orientados giram em uma velocidade determinada pela força do campo magnético. Ao aplicar uma radiação com a mesma frequência de giro dos prótons, o próton sairá do alinhamento determinado pelo campo. Quando os prótons voltam ao alinhamento com o campo, elas emitem de volta uma frequência de radiação que é captada pela máquina de exame. A velocidade de retorno varia conforme o tecido, permitindo que se determine a existência de diferentes tecidos (ex.: matéria banca e matéria cinza) [FM10].

O sangue contém hemoglobina que são moléculas que contém ferro. O ferro da hemoglobina tem efeito de distorção do campo magnético provocado pela máquina, causando uma deflexão dos prótons orientados. A taxa de deflexão das moléculas é medida pela máquina de MRI. Um importante fator é que a molécula de hemoglobina oxigenada (oxihemoglobina) tem efeitos magnéticos diferentes da hemoglobina desoxigenada (desoxihemoglobina), o que causa um efeito defletor diferente nos prótons orientados pelo campo. A medida de 
deflexão dos prótons causada pelas moléculas de hemoglobina é chamado de sinal BOLD (blood-oxygen-level dependent) [Bux02].

Importante observar que ao dilatar os vasos sanguíneos, a disponibilidade de oxigênio aumenta mais que o consumo, fazendo com que áreas de maior atividade cerebral tenham proporcionalmente mais hemoglobina oxigenada do que desoxigenada. Com a mensuração do sinal BOLD nós inferimos as regiões de maior atividade em decorrência das regiões que estão com maior quantidade de hemoglobina oxigenada.

O sinal BOLD é uma medida indireta de atividade cerebral, pois não mede diretamente a ativação do neurônio, mas uma diferença no fluxo sanguíneo da região adjacente. Dessa forma, a medida obtida é referente a um pequeno volume cerebral chamado de voxel. Outro ponto problemático é a variação do sinal BOLD que, conforme representado na Figura 4.2, leva em média dois segundos para aumentar a partir do estímulo recebido e chega em seu máximo por volta de seis segundos e volta ao estado normal em uma taxa similar seguido de uma leve queda abaixo da taxa normal [SBJ13, Log03], o que deve ser considerado ao avaliar ativação causada por estímulos externos.

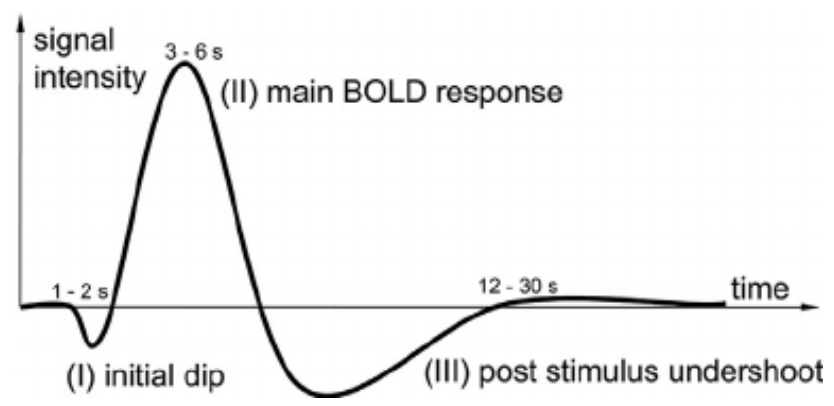

Figura 4.2: Variação do sinal BOLD a partir de um estímulo externo. O estímulo acontece no instante zero, o sinal BOLD cai devido ao consumo de oxigênio inicial seguido de um pico desencadeado pela atividade. O fluxo sanguíneo deixa de ser aumentado e o sinal BOLD cai até se estabilizar por volta de 12 a 30 segundos. Retirado de Siero e colegas [SBJ13].

\subsection{Séries Temporais}

Como comentado anteriormente na seção 4.1, é feita uma mensuração para cada pequeno pedaço tridimensional de tecido cerebral chamado voxel. Esta medida é repetida para cada voxel em vários instantes de tempo durante o exame. O conjunto dessas medidas resulta em uma série temporal para cada voxel do cérebro, como exemplificado na Figura 4.3. Esta série temporal representa a variação da atividade do voxel durante o exame, o que permite avaliar a relação da região com a tarefa sendo executada, para o caso de exames com tarefas específicas e análises estatísticas como, por exemplo, inferir regiões que estejam sendo ativadas conjuntamente, indicando uma conectividade funcional, como melhor explicado na seção 4.6. 


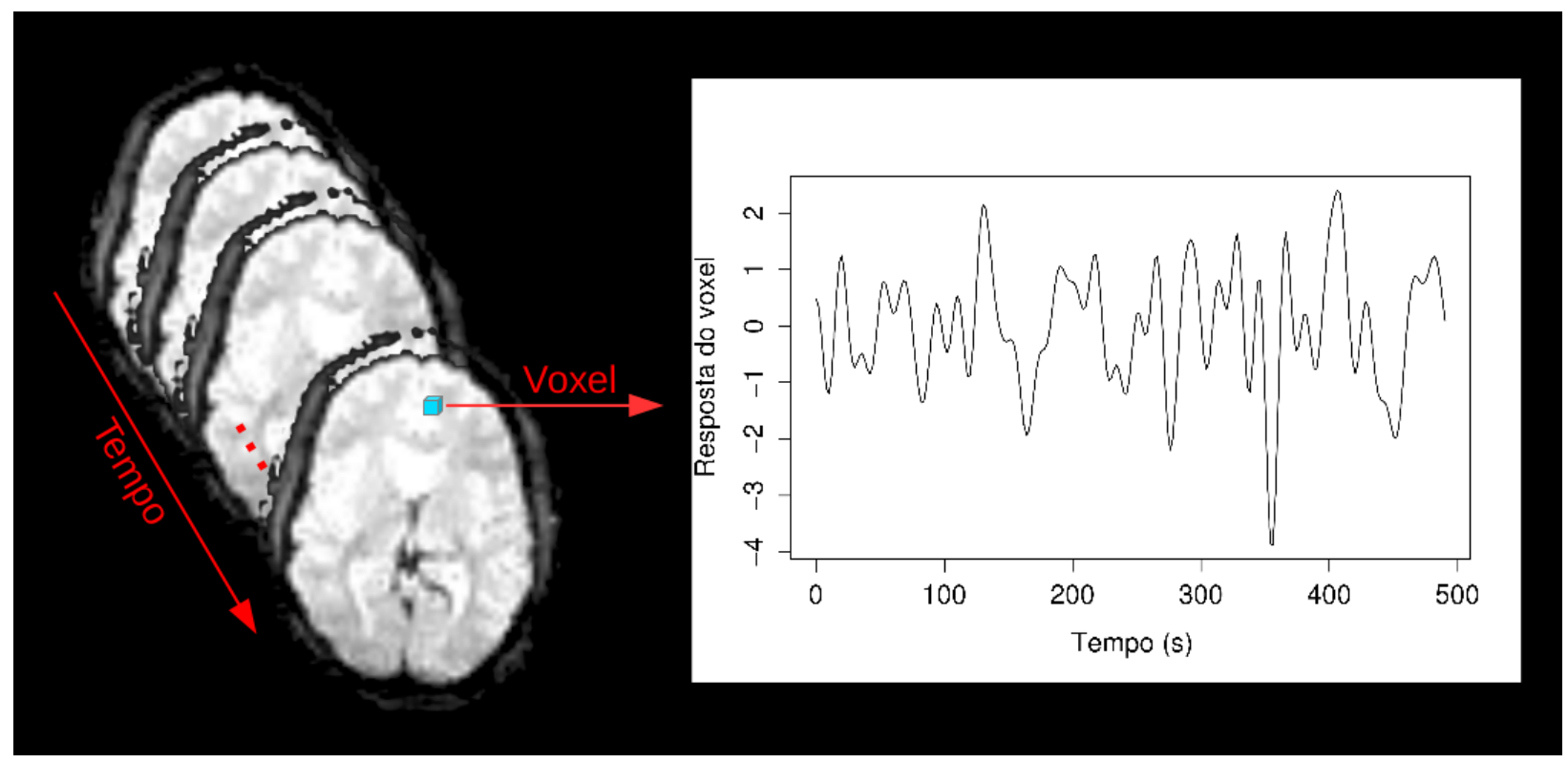

Figura 4.3: Exemplo de aquisição dos dados no tempo. É feita uma mensuração para cada voxel em cada instante de tempo. O conjunto de todas as medições de um mesmo voxel no tempo é uma série temporal da variação do voxel durante o exame. Imagem retirada de Vidal [Vid14].

\subsection{Pré-processamento}

A aquisição dos dados de séries temporais está sujeita à diversos tipos de ruídos e não uniformidades que dificultam a análise comparativa dos dados, como por exemplo: a coleta dos dados está sujeita a possíveis interferências com o campo magnético da máquina, o que pode gerar ruídos [OTM ${ }^{+}$92, FM10]; a aferência do sinal é feita por fatias do cérebro, havendo uma diferença de tempo entre uma fatia e outra; os tamanhos e formatos das cabeças dos indivíduos não são uniformes, o que dificulta uma comparação direta; o indivíduo pode se mexer dentro da máquina, causando erros quanto à localização do voxel no espaço [PMN11].

Apesar dos laboratórios executarem procedimentos para tentar minimizar os ruídos durante a coleta, ainda é necessário executar um pré-processamento para minimizar os efeitos anteriormente descritos. Em geral, os próprios laboratórios fazem um pré-processamento dos dados, mas como o procedimento de pré-processamento também pode influenciar o resultado final, é desejável que o mesmo procedimento seja executado para todos os dados de todos os laboratórios utilizados.

De modo geral, os objetivos do pré-processamento dos dados são minimizar os ruídos e melhorar a qualidade do sinal que se deseja analisar, por exemplo isolando o sinal de alta ou de baixa frequência, conforme a análise que se deseja fazer [SBJ13]. Nas subseções seguintes faremos uma breve apresentação de procedimentos comumente utilizados para o pré-processamento de dados de fMRI. 


\subsubsection{Correção da Temporização de Fatias}

A aquisição dos dados durante o exame de fMRI é feita por fatias de cérebro uma em cada instante de tempo e uma imagem completa do cérebro é feita a partir de todas as fatias coletadas em um mesmo tempo de repetição (TR, do inglês repetition time). A aquisição geralmente é feita em ordem crescente ou decrescente, mas também pode ser feito de forma intercalada coletando primeiro todas as fatias ímpares e depois todas as pares, por exemplo [PMN11].

Esta diferença do tempo da aquisição das fatias gera alguns problemas para a análise dos dados, pois a maior parte das técnicas de análise considera que todos os voxels de uma imagem completa do cérebro foram adquiridas no mesmo instante de tempo. Como ilustrado na Figura 4.4, ao comparar a série temporal de um voxel na fatia um e na oito, poderíamos concluir que as séries refletem atividades diferentes, quando na verdade se tratam da mesma resposta hemodinâmica registrada com diferença de alguns segundos entre as fatias. A correção de temporização de fatias (do inglês slice time correction foi criada para amenizar os efeitos dessa diferença de temporização [PMN11].

A forma mais comum de correção de temporização de fatias é escolher uma das fatias como referência e interpolar os dados de todas as outras para que todas tenham o mesmo tempo de referência [PMN11]. Um dos principais problemas desta técnica é que artefatos em uma fatia podem ser propagados para outras fatias, por tanto, o uso desta técnica deve ser avaliado cuidadosamente.

\subsubsection{Correção de Movimento}

Indivíduos que passam por um exame de fMRI costumam apresentar algum tipo de movimentação da cabeça, mesmo que sutil, como a causada pelo ato de engolir saliva, por exemplo. Esta movimentação da cabeça pode causar principalmente dois tipos de problema. O primeiro é quando o indivíduo muda permanentemente a posição da cabeça alterando a posição dos voxels no espaço e não retornando à posição original. Isto pode causar problemas para determinar a série temporal completa do voxel, pois parte da série será registrada em outras coordenadas no espaço. As técnicas de movimentação da cabeça costumam focar em corrigir este tipo de erro. O segundo tipo de erro que pode ocorrer é uma falsa ativação positiva ou negativa em decorrência da movimentação, principalmente nas bordas. Um voxel que não estava registrando sinal, pois não possuía tecido cerebral naquela região pode passar a registrar sinal e indicar que ocorreu uma ativação em decorrência da diferença de sinal. O mesmo pode ocorrer no voxel que apresentava ativação e passou a não apresentar ativação, pois não há mais tecido cerebral na região [PMN11, SBJ13]. Este tipo de artefato é demonstrado na Figura 4.5.

Para a correção deste problema, utiliza-se geralmente técnicas baseadas em movimentação de corpo rígido (do inglês rigid body transformation) que assume que a cabeça pode se movimentar nos três eixos, mas não muda sua forma. A correção é feita realinhando a 

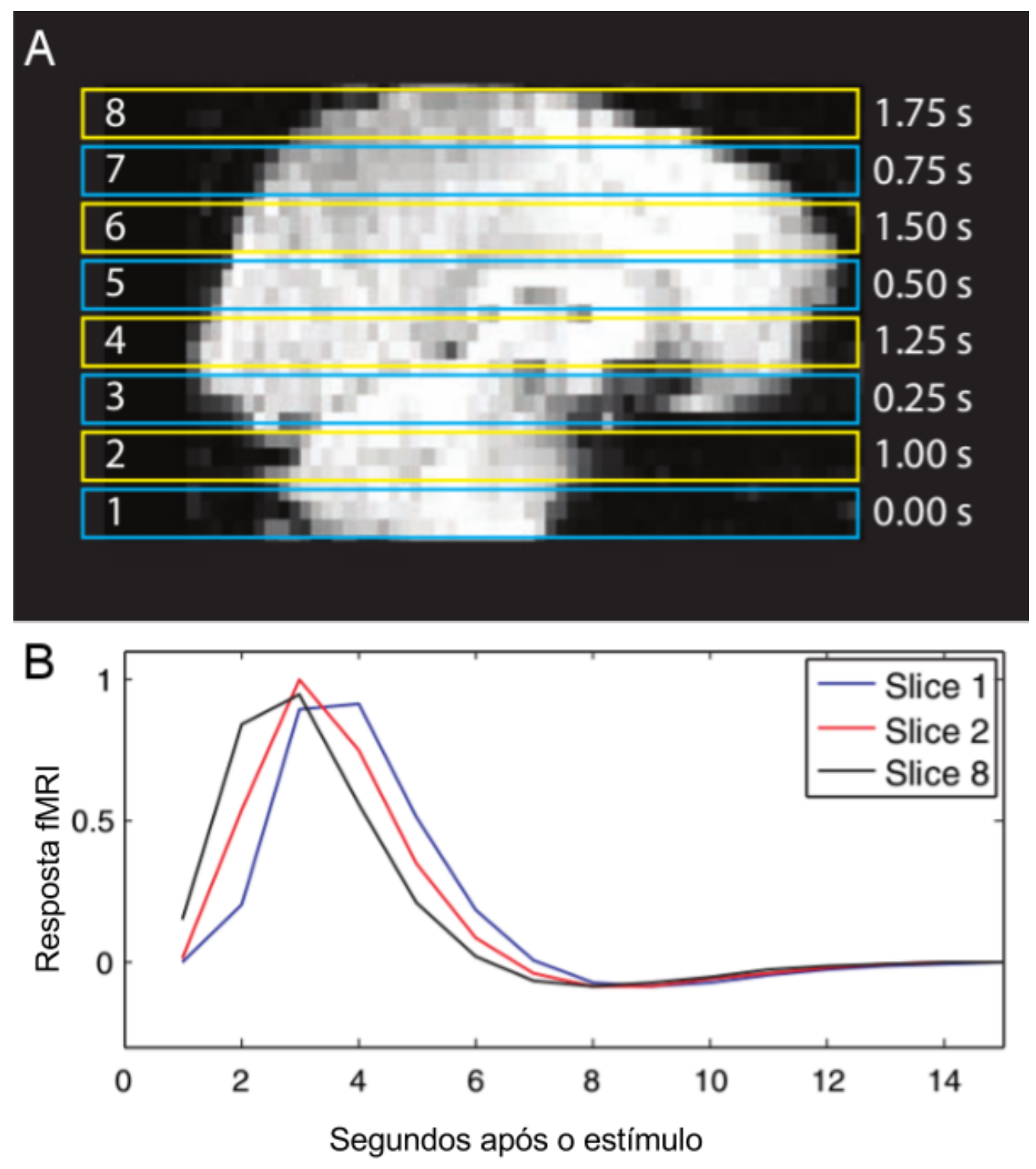

Figura 4.4: Exemplo de problema que pode ocorrer ao coletar fatias em tempos diferentes. (A) Exemplo de cérebro dividido em fatias de aquisição de imagem. As fatias foram coletadas em ordem crescente primeiro as impares e depois das pares. (B) Exemplo de como seria registrada a mesma resposta hemodinâmica em cada uma das fatias. Quando é feita a leitura da fatia 1, a resposta hemodinâmica ainda não começou, porém, quando a leitura chega na fatia 8, a resposta hemodinâmica já estava acontecendo. Imagem adaptada de Poldrack [PMN11].

imagem obtida à sua posição original [PMN11].

Utiliza-se a hipótese de corpo rígido para estimar as seis movimentações (três rotações e três translações) que minimizam a diferença entre a imagem no dado instante de tempo e a primeira imagem coletada no exame. Então, estes parâmetros são utilizados para deslocar a imagem para sua posição original por interpolação [PMN11].

Importante ressaltar que esta correção não elimina completamente os efeitos que a movimentação da cabeça pode gerar. Como o fMRI se baseia na velocidade de rotação do próton prevista para calcular o retorno e estimar o sinal, e esta velocidade de rotação varia conforme a posição do tecido cerebral no campo, a movimentação da cabeça durante o exame 

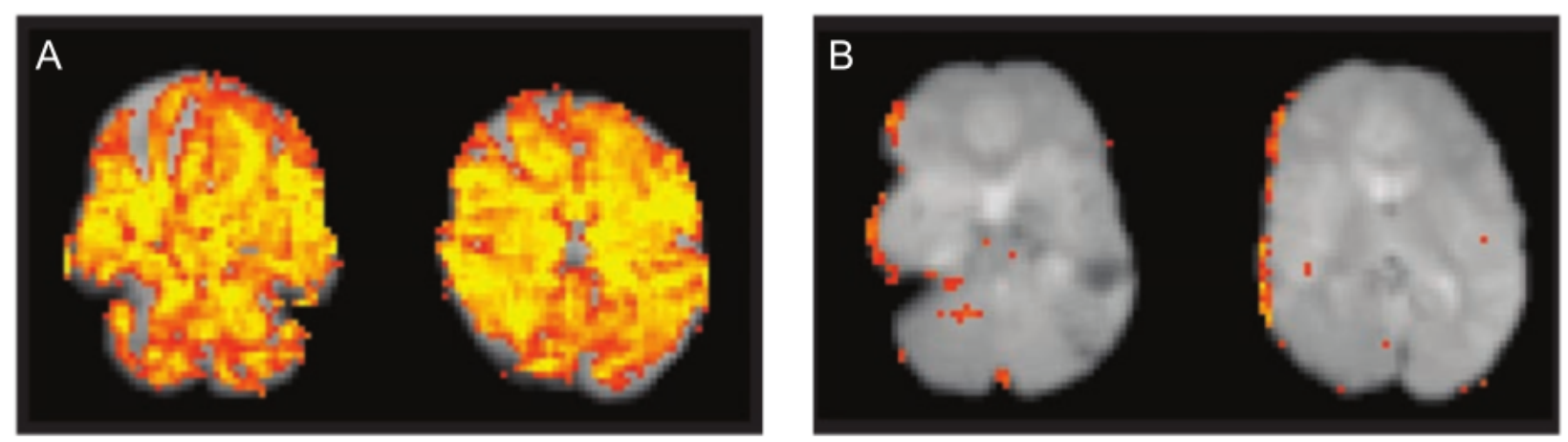

Figura 4.5: Exemplo de problemas causados por movimentação da cabeça. (A) Dois cortes de uma imagem de paciente com síndrome de Tourette com movimentação intensa durante o exame dando origem à artefatos conhecidos como flamming bain. (B) Dois cortes de uma imagem de paciente com leve movimentação dando origem a um caso mais comum de artefatos na borda esquerda. Imagem adaptada de Poldrack [PMN11].

pode gerar artefatos devido a um erro de previsão dessa velocidade de rotação. Este efeito é conhecido como spin history effect $\left[\mathrm{FWH}^{+} 96\right]$.

\subsubsection{Pipeline de Pré-processamento}

Existem programas que auxiliam a aplicação das técnicas de correção nas imagens como por exemplo o SPM (Statistical Parametric Mapping ${ }^{1}$ ), o AFNI (Analysis of Functional Neuroimages $^{2}$ ) e o FSL (FMRIB Software Library ${ }^{3}$ ). Também existem diversos pipelines que são descrições de passos a serem adotados para pré-processar os dados conforme recomendado por um laboratório ou um grupo. Neste trabalho utilizamos o pipeline athena ${ }^{4}$ e os passos estão representados na Figura 4.6.

Como descrito na seção 4.3.2, a correção de movimentação da cabeça não corrige possíveis artefatos causados por erros de leitura devido à movimentação da cabeça. Para poder remover volumes cerebrais com artefatos que podem prejudicar a análise, utilizamos a técnica de scrubbing $\left[\mathrm{PBS}^{+} 12\right]$. Esta técnica consiste em utilizar os estimadores de movimentação da cabeça para criar um estimador de qualidade chamado frame displacement (FD) e a diferença de intensidade entre os pontos da série temporal do voxel para criar outro estimador de qualidade chamado temporal derivative of timecourses - RMS variance over voxels (DVARS). Estes estimadores de qualidade são utilizados para escolher quais volumes devem ser retirados para evitar os problemas descritos em 4.3.2.

Neste trabalho, utilizamos dados cujo pipeline de pré-processamento foi executado pelo aluno Maciel C. Vidal previamente em seu trabalho de mestrado [Vid14]. Desta forma, já trabalhamos com dados corrigidos.

\footnotetext{
${ }^{1}$ http://www.fil.ion.ucl.ac.uk/spm/

${ }^{2}$ http://afni.nimh.nih.gov/afni

${ }^{3}$ http://fsl.fmrib.ox.ac.uk/fsl/fslwiki/

${ }^{4}$ http://www.nitrc.org/plugins/mwiki/index.php/neurobureau:AthenaPipeline
} 


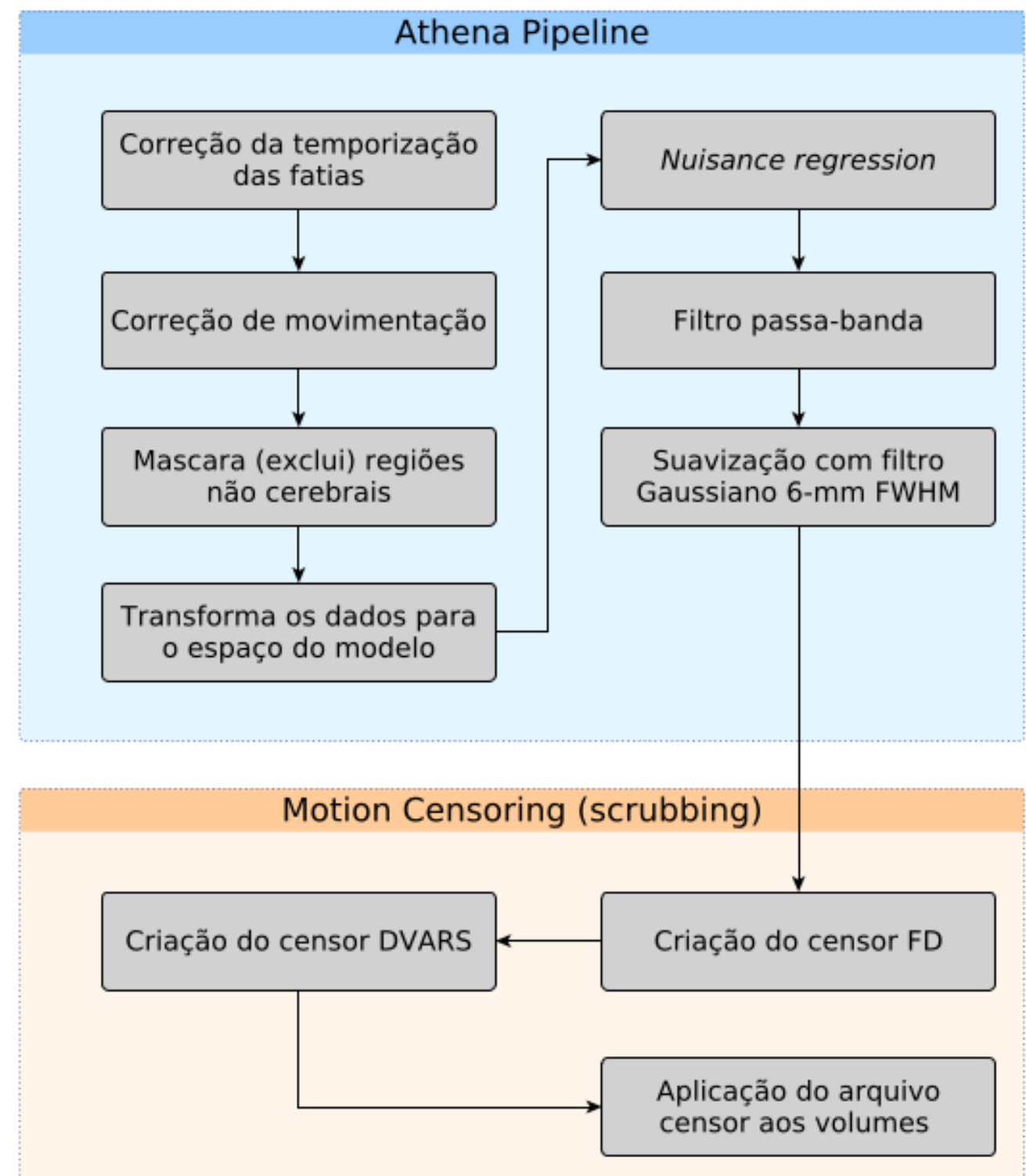

Figura 4.6: Etapas para o pré-processamento dos dados fMRI. Imagem retirada de Vidal. [Vid14]

\subsection{Atlas AAL}

Um atlas fornece um guia para a identificação de características anatômicas em um espaço de coordenadas. Um template é uma imagem representativa do atlas sobre o qual se pode alinhar imagens individuais, servindo de base para visualizar a imagem de um indivíduo ou da média de um grupo. Os atlas são úteis para localização das regiões de ativação e auxiliam na interpretação dos resultados, e os templates são fundamentais para a normalização dos dados.

O atlas Automated Anatomical Labelling (AAL) foi desenvolvido por uma equipe de pesquisa da França utilizado em pesquisas de análise funcional do cérebro. Ele se baseia nos sulcos cerebrais para criar divisões anatômicas. Esta divisão foi feita com base em um atlas MNI pré-existente sobre o qual os pesquisadores indicaram os sulcos principais e um software fez a inferências de 45 regiões anatômicas em cada um dos hemisférios e 26 regiões 
anatômicas no cerebelo, totalizando 116 regiões anatômicas $\left[\mathrm{TMLP}^{+}\right.$02], como representado na Figura 4.4. Este foi o atlas utilizado neste trabalho.

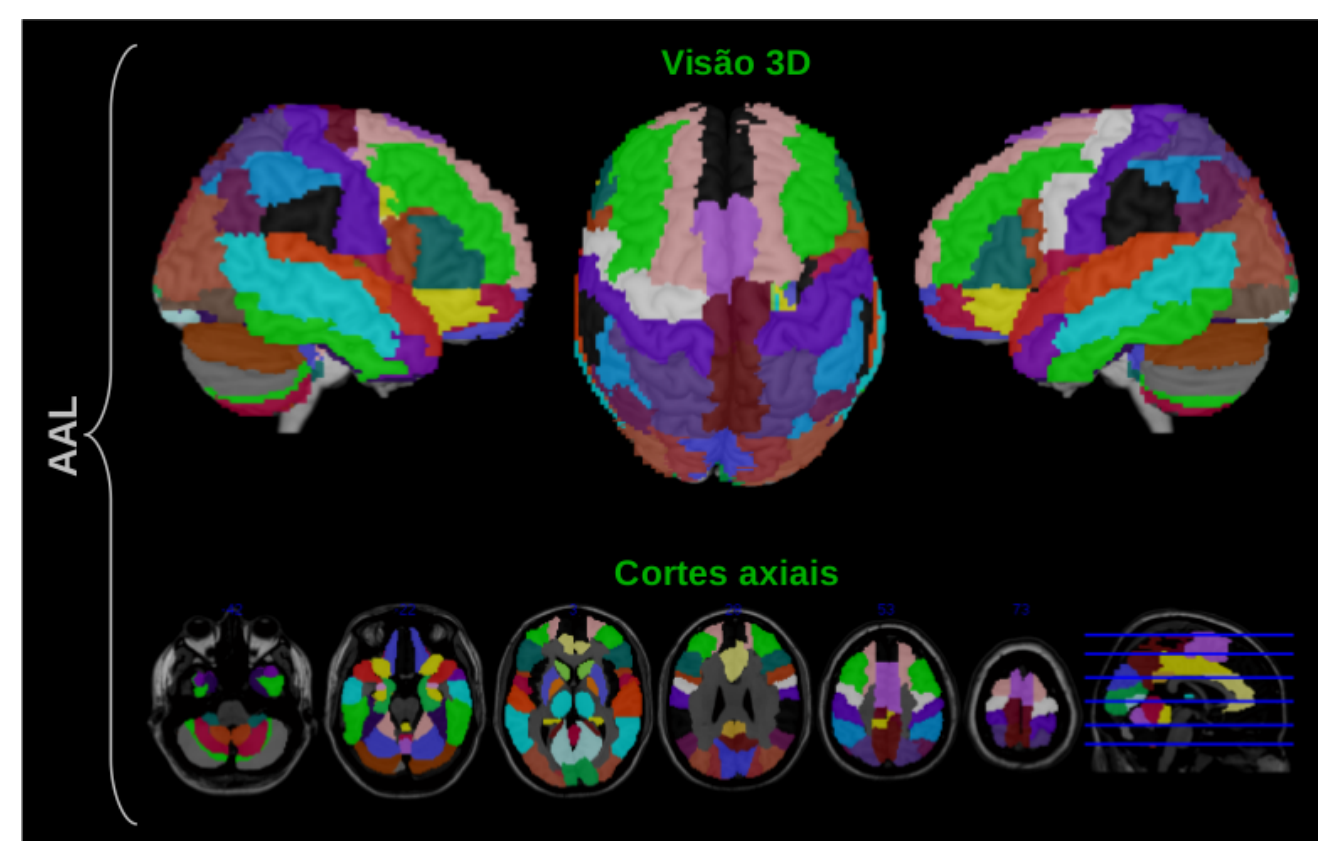

Figura 4.7: Representação 3D do atlas AAL. Imagem retirada de Vidal [Vid14].

\subsection{Região de Interesse}

Cada volume cerebral, conjunto de fatias em um dado instante de tempo, possui centenas de milhares de voxels. Para facilitar as análises, é possível utilizar regiões de interesse (do ingles Regions of Interest ROI). Utilizamos como base a divisão do atlas explicado na subseção 4.4 para agregar voxels em ROIs restringindo o estudo em menos regiões com áreas cerebrais maiores.

Uma das motivações para a análise baseada em ROIs é limitar o erro tipo I, rejeitar a hipótese nula quando ela é verdadeira. Ao restringir o número de regiões estudadas, restringimos também o número de testes realizados. Esta restrição é necessária pois, ao corrigirmos para múltiplos testes, a abordagem utilizada pode ser muito conservadora, resultando em erro tipo I quando o número de comparações é muito alto. Uma segunda motivação seria limitar o estudo à uma região anatômica que se relaciona com a condição estudada baseado em estudos prévios (por exemplo, estudar o lobo frontal para casos de psicopatia) [PMN11]. Outra vantagem da utilização de ROIs é melhorar a interpretação dos dados, já que na literatura encontramos descrições de funções por regiões anatômicas.

\subsubsection{Definição das Regiões de Interesse}

ROIs podem ser definidas tanto com base em características funcionais como estruturais. As ROIs com base em características estruturais são usualmente definidas com bases em 
estruturas macroscópicas, como a divisão por giros. Geralmente é preferível que se faça a divisão anatômica com base em cada um dos indivíduos, já que pode haver diferença significativa entre indivíduos. Apesar disso, em estudos que utilizam grande número de indivíduos pode ser preferível utilizar ROIs baseadas em atlas de divisão anatômica para minimizar o trabalho manual, porém, é importante observar que em atlas baseados em um único indivíduo e que fazem divisões em áreas pequenas, a chance de sobreposição correta com os indivíduos estudados é pouca, podendo ocasionar erros no estudo.

Após dividir o cérebro em ROIs, é preciso extrair uma série temporal que represente o sinal médio para a ROI. Isto pode ser feito de diversas formas, uma técnica simples e antiga era utilizar a quantidade de voxels ativos dentro de uma ROI como representação da ativação da ROI no instante de tempo, porém, está técnica é problemática, pois depende do valor de corte estabelecido para definir um voxel ativo.

Outra abordagem mais utilizada hoje em dia é o cálculo da média da ativação dos voxels dentro de uma ROI como a ativação da ROI. Essa abordagem possui o problema de possivelmente amenizar sinais de ativação em casos em que uma pequena parte da ROI está ativada e uma grande parte não apresenta ativação. Uma alternativa é a extração da componente principal da ROI, o que possui a vantagem de não atenuar o sinal, porém, só representa o processo mais significativo acontecendo na ROI. Não existe uma solução perfeita para a forma de calcular a série representativa da ROI. É preferível que se utilize ROIs pequenas para evitar grandes erros na tentativa de extrair o sinal médio da ROI.

\subsection{Conectividade Funcional}

Um dos principais focos da neurociência é entender os meios biológicos que dão origem às atividades cognitivas. Esta ideia se baseia no conceito de que a cognição emerge de eventos cerebrais e que o comportamento pode ser explicado por processos neurais [FM10]. Um dos princípios fundamentais que dão base a essa ideia é a relação entre atividade neural e fluxo sanguíneo, como explicado na seção 4.1, que surgiu da observação de aumento do fluxo sanguíneo cerebral durante atividades cognitivas. Mais recentemente, utilizando técnicas de neuroimagem atuais como o PET e o fMRI é possível observar áreas cerebrais ativas durante processos cognitivos em voluntários $\left[\mathrm{IBH}^{+} 01\right]$.

No princípio da neurociência a funcionalidade de cada região cerebral era estimada com base na observação de sintomas associados a casos clínicos com lesões pontuais. Estas observações que tentavam relacionar regiões anatômicas do cérebro com uma função específica deram origem à teoria de especialização funcional (ou segregação funcional). Apesar desta teoria ser bem estabelecida e ser a base para os princípios da organização cortical, hoje a neurociência cognitiva tem se focado no estudo da interação entre as áreas para execução de atividades cognitivas específicas, ao que chamamos integração funcional. Esta ideia vem desde os experimentos de Mishkin e Ungerleider [MU82], nos quais eles descreveram cami- 
nhos de conexões separados para atividades visuais de identificação e localização de objetos. Estudos de covariação de resposta BOLD em regiões corticais separadas tem sido propostos como evidências para este modelo. A essa relação entre regiões corticais separadas para a execução de uma mesma tarefa chamamos de conectividade funcional.

A conectividade funcional não reflete diretamente a conectividade efetiva, pois não necessariamente duas regiões cuja ativação está correlacionada apresentam uma via física de ligação entre elas. É possível, por exemplo, que duas regiões de conectividade funcional estejam recebendo impulsos de uma terceira região em comum, o que geraria uma correlação na atividade de ambas as regiões sem que haja uma ligação física entre elas.

Sabe-se que o cérebro em estado de repouso, isto é, não executando tarefas específicas, apresenta flutuações de sinais variando de intensidade no tempo. Biswal demonstrou que as regiões conhecidas por apresentarem ativação em uma tarefa motora apresentavam grande correlação na flutuação do sinal em estado de repouso e que esta correlação poderia ser usada para estimar regiões que atuam em tarefas semelhantes usando imagens em estado de repouso [BYHH95]. A Figura 4.8 mostra o resultado dos experimentos de Biswal. A imagem à esquerda mostra as regiões de atividade cerebral durante a tarefa de movimentação de dedos em ambas as mãos. A imagem à direita foi construída a partir da flutuação de atividade em estado de repouso em que foi selecionado um voxel da região motora esquerda (b) como referência. Os voxels que apresentaram coeficiente de correlação $>0.35$ com o voxel referência foram coloridos na imagem. Os voxels em amarelo apresentam correlação negativa. Podemos observar pelas imagens que existe uma alta sobreposição das regiões, indicando que as flutuações em estado de repouso se aproximam das regiões de conectividade funcional.

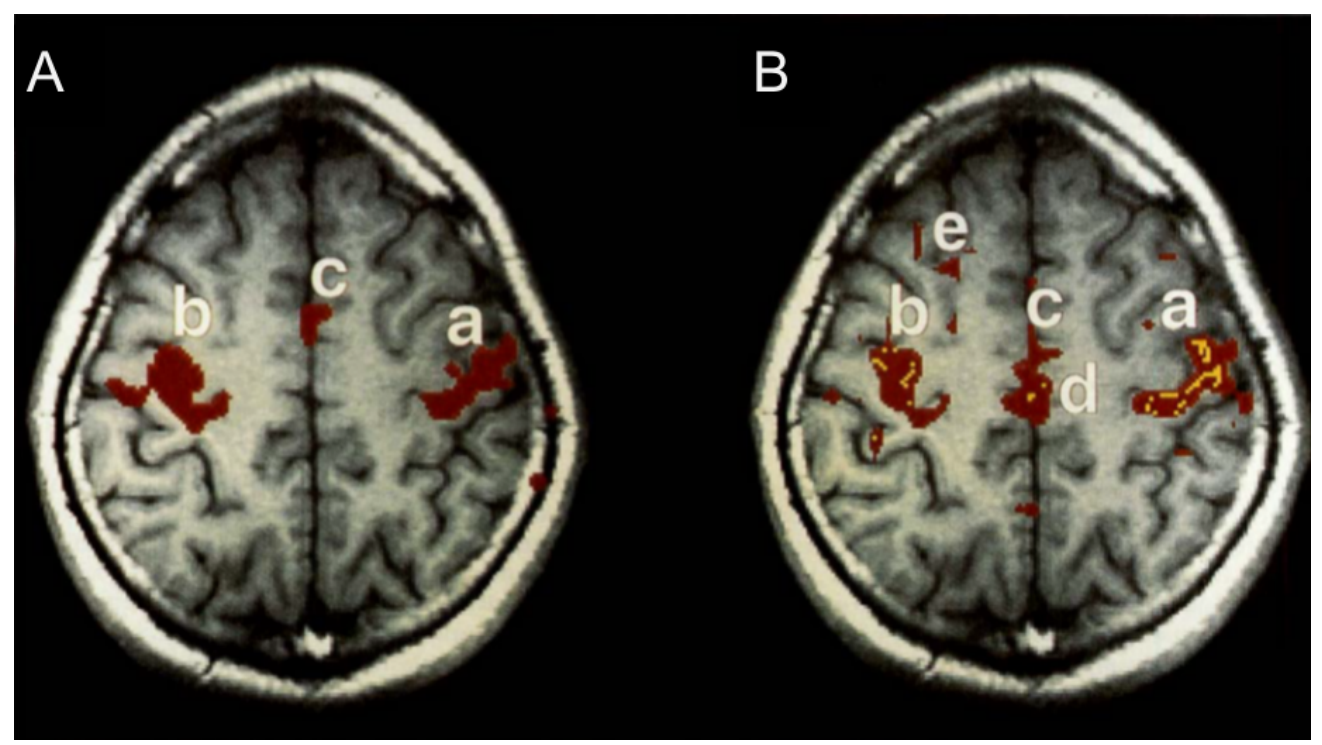

Figura 4.8: Imagem dos experimentos realizados por Biswal. (A) Regiões ativas durante atividade de movimentação de dedos de ambos os dados. (B) Áreas correlacionadas com a série temporal de um voxel escolhido da região do córtex motor esquerda. Áreas vermelhas mostram correlação positiva e áreas amarelas correlação negativa. Imagem adaptada de Biswal [BYHH95] 


\section{Capítulo 5}

\section{Aplicação em Dados Reais}

Com base na revisão bibliográfica apresentada nos capítulos anteriores, formulamos a seguinte hipótese: a conectividade funcional entre córtex e cerebelo é diferente no grupo TEA em relação ao grupo DT. Nesta seção utilizaremos os conceitos apresentados na seção 4.6 para estimar a conectividade funcional entre córtex e cerebelo para a média de cada um dos grupos (DT e TEA) e testar a hipótese apresentada.

\subsection{Banco de Dados}

Para este estudo utilizamos o banco de dados Autism Brain Imaging Data Exchange (ABIDE), que está disponível publicamente no website do projeto ${ }^{1}$.

A iniciativa ABIDE unificou dados de ressonância magnética funcional e estrutural de 17 laboratórios totalizando exames de 1.112 indivíduos, dos quais 573 são indivíduos com desenvolvimento típico e 539 foram diagnosticados com TEA. Para alguns dos laboratórios existem informações adicionais de fenótipo como: mão de preferência da escrita, QI, resultados ADI e ADOS (para o grupo TEA), idade, gênero, entre outros.

Este banco de dados é de grande importância para o estudo do TEA, pois unifica uma grande quantidade de dados e informações que de outra forma seria muito difícil conseguir considerando os custos e tempo necessários para a coleta deste tipo de exame.

\subsection{Seleção de Participantes}

Os dados do banco de dados ABIDE foram pré-processados seguindo o pipeline Athena pelo aluno Maciel C. Vidal em seu trabalho de mestrado [Vid14]. Após o processo de scrubbing, os indivíduos que tiveram séries temporais com menos de 100 pontos foram removidos. Os indivíduos que tiveram mais de $5 \%$ dos volumes removidos pelo scrubbing também não foram incluídos para garantir qualidade dos dados analisados. Após este processo restaram 708 indivíduos (432 DT e 276 diagnosticados com TEA). Indivíduos diagnosticados com

\footnotetext{
${ }^{1}$ http://fcon_1000.projects.nitrc.org/indi/abide/
} 
autismo ou Asperger foram considerados como parte do espectro autista, como determinado no manual de diagnóstico e estatística dos transtornos mentais 5a. edição (DSM-5)[Ass13]. As faixas de idade dos grupos são de 6.47 - 56.2 (18.21 \pm 8.04) anos no grupo DT e 7.13 - 58 $(18.42 \pm 8.38)$ anos no grupo TEA. Setenta e nove participantes do grupo TEA faziam uso de algum medicamento no momento do exame, e um participante de grupo DT fazia uso de medicamento. Foram selecionados participantes de ambos os sexos sendo 84 feminino e 348 masculino no grupo DT e 35 feminino e 241 masculino no grupo TEA.

\subsection{Regiões de Interesse}

Utilizamos o atlas Automated Anatomical Labeling (AAL) $\left[\mathrm{TMLP}^{+} 02\right]$ para fazer a divisão dos volumes cerebrais em 116 ROIs. Utilizamos um atlas do Montreal Neurological Institute (MNI) para identificar ROIs que tivessem alguma intersecção com o ventrículo e removemos estas regiões do grupo de ROIs do córtex para evitar resultados devido a artefatos [PMN11].

Separamos apenas as ROIs do cerebelo e verificamos a qualidade da leitura da região no grupo de estudo a fim de evitar utilizar regiões sem leitura. Para cada indivíduo, somamos a quantidade de voxels lidos para cada ROI, dividimos pela quantidade de voxels totais da ROI e multiplicamos por cem para obter a porcentagem de leitura da ROI para cada indivíduo. Em seguida, fizemos a média da porcentagem de cada ROI para toda a população. O resultado está ilustrado na Figura 5.1, onde podemos ver que as regiões com melhor leitura são o lobo anterior e o vérmis cerebelar. Para garantir a qualidade da análise, utilizamos apenas as ROIs destas regiões citadas, excluindo as ROIs do lobo posterior.

Após as remoções, restaram um total de 79 ROIs, sendo 65 do córtex e 14 do cerebelo.

\subsection{Análise de Conectividade Funcional Córtico-Cerebelar}

Conforme descrito na seção 4.6, a conectividade funcional é uma inferência de regiões que atuam em conjunto para execução de tarefas a partir da análise de sinais correlacionados entre as regiões. Para inferir a conectividade córtico-cerebelar, nós optamos por analisar a correlação do sinal de cada ROI do córtex cerebral com o conjunto de ROIs do cerebelo. Esta medida foi adotada principalmente por dois motivos: (1) fazer a análise de cada ROI do córtex com cada uma das ROIs do cerebelo dois a dois resultaria em um grande número de comparações e ao corrigir os resultados para múltiplos testes perderíamos muito em poder estatístico; (2) devido à plasticidade neural, seria possível que o cerebelo de indivíduos com TEA executasse funcionalidades em outras regiões diferentes das regiões em indivíduos de DT, porém, isso não significaria necessariamente uma falha na funcionalidade ou na conectividade córtico-cerebelar. Por não sabermos qual região do cerebelo está conectada com o córtex, testamos a conectividade da ROI do córtex com a totalidade do cerebelo. 


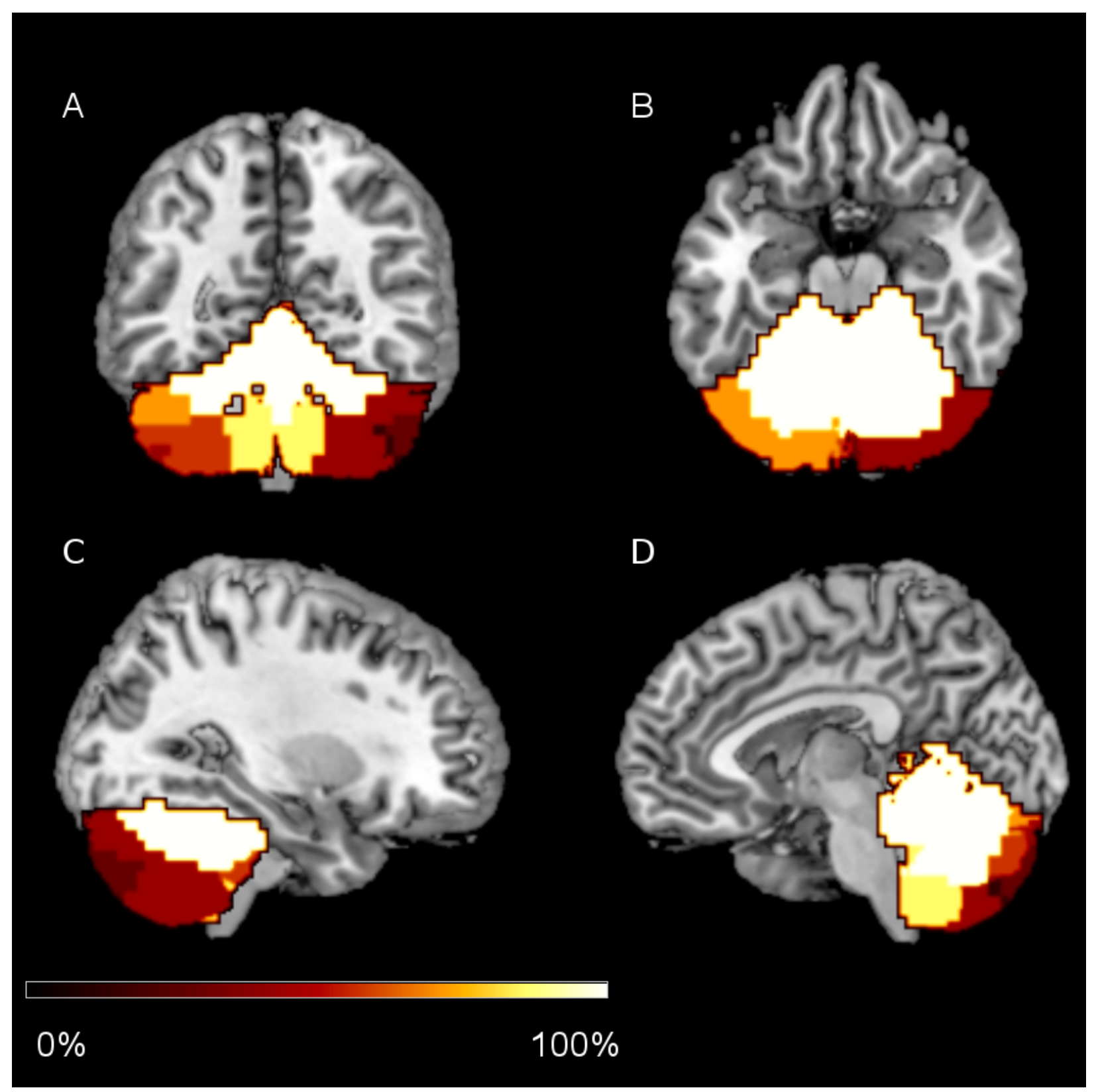

Figura 5.1: Mapa de calor indicando em cor mais clara as ROIs com maior média de porcentagem de leitura no grupo de estudo e em cor mais escuras as ROIs com menor porcentagem de leitura. $(A, B, C)$ áreas mais claras na região do lobo anterior e lóbulo VI, áreas mais escuras na região do lobo posterior. (D) área clara na região do vérmis cerebelar.

Para fazer esta análise de correlação de cada ROI do córtex com o cerebelo, desenvolvemos um modelo linear para identificar o quanto as ROIs do cerebelo explicavam o sinal de cada ROI do córtex. As ROIs do cerebelo são pequenas de forma que a resposta hemodinâmica de uma região pode ativar mais de uma ROI, o que resulta em multicolinearidade entre as séries temporais das ROIs. Seria problemático tentar estimar os coeficientes de regressão para variáveis preditoras com multicolinearidade, então utilizamos o método de análise de componentes principais (PCA) em conjunto com a regressão linear. O PCA é utilizado para reduzir a dimensionalidade de um conjunto de dados onde as variáveis são muito correlacionadas entre si. Esta redução é feita com uma transformação para um novo conjunto de 
variáveis em coordenadas ortogonais que são ordenadas de tal forma que as primeiras variáveis contém a maior parte da variação presente em todo o conjunto original de variáveis. Estas novas variáveis são conhecidas pelo nome de componentes principais (PCs) [Jol13]. O método de utilização do PCA em variáveis preditoras de uma regressão linear é conhecido como regressão de componentes principais e consiste em simplesmente utilizar os PCs das variáveis preditoras em vez das variáveis preditoras originais na regressão. Removendo os PCs de menor variância, podemos melhorar a estimativa dos coeficientes da regressão.

Neste trabalho nós optamos por utilizar os primeiros PCs que contém no mínimo 95\% da variância dos dados para garantir pouca perda de informação. O cálculo dos PCs para as séries temporais do cerebelo foi feito para cada indivíduo separadamente e a quantidade de PCs adotado em cada regressão também foi determinada independentemente para cada indivíduo. Chamaremos esta quantidade de PCs adotado para cada indivíduo de $p$. Após a determinação dos $p$ PCs para cada indivíduo uma regressão linear para cada ROI do córtex para cada indivíduo foi executada, sendo a variável resposta a série da ROI do córtex e as variáveis preditoras os $p$ PCs selecionados. Formalizamos a operação descrita a seguir:

Seja y o vetor contendo $n$ pontos da série temporal de uma ROI do córtex de um indivíduo, $\mathbf{X}$ uma matriz $(n \times 14)$ que contém $n$ pontos da série temporal de cada uma das 14 ROIs do cerebelo sendo $\mathbf{X}(i, j)$ o i-ésimo ponto da série temporal da ROI j, $\boldsymbol{\beta}$ o vetor contendo 14 coeficientes da regressão, um para cada ROI do cerebelo e $\boldsymbol{\epsilon}$ o vetor de $n$ termos de erro. Então, temos o modelo de regressão desejado para determinar a correlação entre o córtex e o cerebelo

$$
\mathbf{y}=\mathbf{X} \boldsymbol{\beta}+\boldsymbol{\epsilon} .
$$

Seja $\mathbf{Z}$ uma matriz $(n \times 14)$ que contém $n$ valores para cada um dos 14 PCs calculados pelo PCA e seja A a matriz de rotação $(14 \times 14)$ de $\mathbf{X}$ formada pelos autovetores de $\mathbf{X}^{\prime} \mathbf{X}$, tal que

$$
\mathbf{Z}=\mathbf{X A}
$$

Sendo $\mathbf{A}$ ortogonal e $\mathbf{A}^{\prime} \mathbf{A}=\mathbf{A} \mathbf{A}^{\prime}=\mathbf{I}$, onde $\mathbf{A}^{\prime}$ a matriz transposta de $\mathbf{A}$ e $\mathbf{I}$ a matriz identidade. Podemos reescrever a equação 5.2 como

$$
\mathrm{ZA}^{\prime}=\mathbf{X A} \mathbf{A}^{\prime}
$$

E a equação 5.1 pode ser reescrita como

$$
\mathbf{y}=\mathrm{ZA}^{\prime} \boldsymbol{\beta}+\boldsymbol{\epsilon}
$$

Chamando $\mathbf{A}^{\prime} \boldsymbol{\beta}$ de $\boldsymbol{\gamma}$ temos o coeficiente para os PCs na regressão que substitui as 
variáveis preditoras por seus PCs

$$
\mathbf{y}=\mathbf{Z} \gamma+\epsilon
$$

Utilizamos o recurso de redução de dimensionalidade usando apenas os $p$ primeiros PCs que somam $95 \%$ da variância para a regressão.

$$
\mathbf{y}=\mathbf{Z}_{p} \gamma_{p}+\boldsymbol{\epsilon}_{p}
$$

Como $\mathbf{Z}_{p}$ mantém $95 \%$ da variância dos dados originais, podemos assumir que o coeficiente de determinação $\left(R^{2}\right)$ do modelo em 5.6 se aproxima do $R^{2}$ do modelo em 5.1. Desta forma, adotamos o $R^{2}$ de 5.6 como uma medida de conectividade funcional entre a ROI do córtex e as ROIs do cerebelo. Assumimos que quanto maior o valor do $R^{2}$, maior é a conectividade funcional entre as regiões.

Para testar se a medida de conectividade funcional é diferente entre os grupos TEA e DT para cada ROI do córtex, nós aplicamos uma segunda regressão linear utilizando a medida de conectividade funcional obtida anteriormente (valor do $R^{2}$ de 5.6) como nova variável resposta e o grupo de diagnóstico (DT ou TEA) como variável preditora. Também adicionamos como co-variáveis idade, gênero e o local de coleta dos dados para remover outros possíveis efeitos.

Seja w um vetor cotendo o valor de $R^{2}$ obtido em 5.6 para cada um dos 708 indivíduos para uma ROI do córtex, g o vetor de 708 elementos que define o grupo de diagnóstico de cada indivíduo sendo 0 DT e 1 TEA, a o vetor de 708 elementos com a idade de cada indivíduos, s o vetor de 708 elementos que define o gênero de cada indivíduo sendo 0 masculino e 1 feminino, L a matriz $(708 \times 16)$ sendo cada coluna representando cada local de coleta possível contendo o valor 1 caso seja o local de coleta dos dados do indivíduo e 0 caso contrário, $\beta_{1}, \beta_{2}$ e $\beta_{3}$ os coeficientes da regressão para $\mathbf{g}, \mathbf{a}, \mathbf{s}$ respectivamente, $\boldsymbol{\beta}_{\mathbf{4}}$ o vetor de 16 coeficientes sendo 1 para cada coluna de $\mathbf{L}$ e $\boldsymbol{\epsilon}$ o vetor de 708 termos de erro.

$$
\mathbf{w}=\mathbf{g} \beta_{1}+\mathbf{a} \beta_{2}+\mathbf{s} \beta_{3}+\mathbf{L} \boldsymbol{\beta}_{\mathbf{4}}+\boldsymbol{\epsilon}
$$

Para garantir que o processo de scrubbing não prejudicou a qualidade dos dados analisados, repetimos os passos descritos utilizando os dados antes e após o processo de scrubbing. Comparamos o p-valor de $\beta_{1}$ obtido em 5.7 para as duas repetições e excluímos as ROIs do córtex para as quais este p-valor teve diferença maior que 0,05. Passaram neste teste de qualidade 63 ROIs. O p-valor de $\beta_{1}$ obtido em 5.7 com dados após scrubbing para estas 63 ROIs foi corrigido utilizando a técnica de controle de taxa de falsas descobertas (do inglês False Discovery Rate FDR) [GLN02] e adotamos o valor de corte de $5 \%$. 


\subsubsection{Análise do Cerebelo}

Nossa análise de conectividade córtico-cerebelar considera a medida de correlação de uma ROI do córtex com todo o cerebelo por motivos citados na seção anterior. Porém, também seria desejável verificar se algumas ROIs específicas do cerebelo apresentam correlação diferenciada com a ROI do córtex. Assim, para cada ROI do córtex cuja conectividade funcional foi considerada significativamente diferente entre os grupos de diagnóstico (DT ou TEA), nós desejamos verificar se existe diferença estatisticamente significativa nos coeficientes de regressão estimados para as ROIs do cerebelo. Em 5.6 nós calculamos os coeficientes de regressão para os PCs calculados para as séries das ROIs do cerebelo. Para obter uma estimativa dos coeficientes de regressão para as variáveis originais, que são as séries das ROIs do cerebelo, aplicamos a seguinte equação na qual $\hat{\boldsymbol{\beta}}$ é o vetor de 14 elementos com os valores dos coeficientes estimados para as variáveis originais, $\boldsymbol{A}_{p}$ é a matriz de rotação $(14 \times p)$ do PCA com colunas limitadas ao número de PCs $p$ e $\gamma_{p}$ é o vetor de coeficientes dos $p$ PCs obtido na equação 5.6 .

$$
\hat{\boldsymbol{\beta}}=\mathbf{A}_{p} \gamma_{p}
$$

Este cálculo foi feito para cada uma das ROIs cujo $\beta_{1}$ corrigido obtido em 5.7 foi menor que 0.05. Então nós obtivemos um vetor $\hat{\boldsymbol{\beta}}$ de medidas de conectividade do cerebelo com cada uma destas ROIs do córtex para cada indivíduo. Para testar se existe diferença entre as medianas das medidas de conectividade de cada ROI do cerebelo com a mesma ROI do córtex para os indivíduos dos grupos DT e TEA, nós utilizamos um teste de Wilcoxon. Escolhemos este teste por ser não-paramétrico e com poder similar ao teste paramétrico t de Student [BH80]. 


\section{Capítulo 6}

\section{Resultados}

\subsection{Análise de Conectividade Funcional Córtico-Cerebelar}

Como resultado de nossas análises obtivemos cinco ROIs com conectividade funcional com o cerebelo diferente entre os grupos: (i) giro fusiforme direito $(p=0.005)$, (ii) giro póscentral direito $(p=0.027)$, (iii) giro superior temporal direito $(p=0.027)$, (iv) giro temporal médio direito $(p=0.005)$ e $(\mathrm{v})$ giro temporal médio esquerdo $(p<0.001)$. A localização cortical das ROIs citadas está demonstrada na Figura 6.1. A Figura 6.2 é uma comparação da medida de conectividade funcional córtico-cerebelar para cada uma das cinco ROIs de diferença significativa para cada um dos grupos (DT e TEA).

\subsection{Análise do Cerebelo}

Em nossa análise exploratória do cerebelo sobre regiões que parecem ter conectividade córtico-cerebelar diferenciadas, nós encontramos algumas regiões que parecem ter influência significativa. A Figura 6.3 mostra para cada ROI do córtex, as ROIs do cerebelo coloridas conforme a diferença entre os grupos de peso da ROI cerebelar na conectividade com a ROI do córtex. As áreas mais claras são ROIs de maior diferença de peso na conectividade, as áreas mais escuras são ROIs de menor diferença. No lobo anterior as ROIs apresentam maior diferença de peso na conectividade no hemisfério direito. Na região do vérmis as ROIs com maior diferença são a III, VIII e IX. 


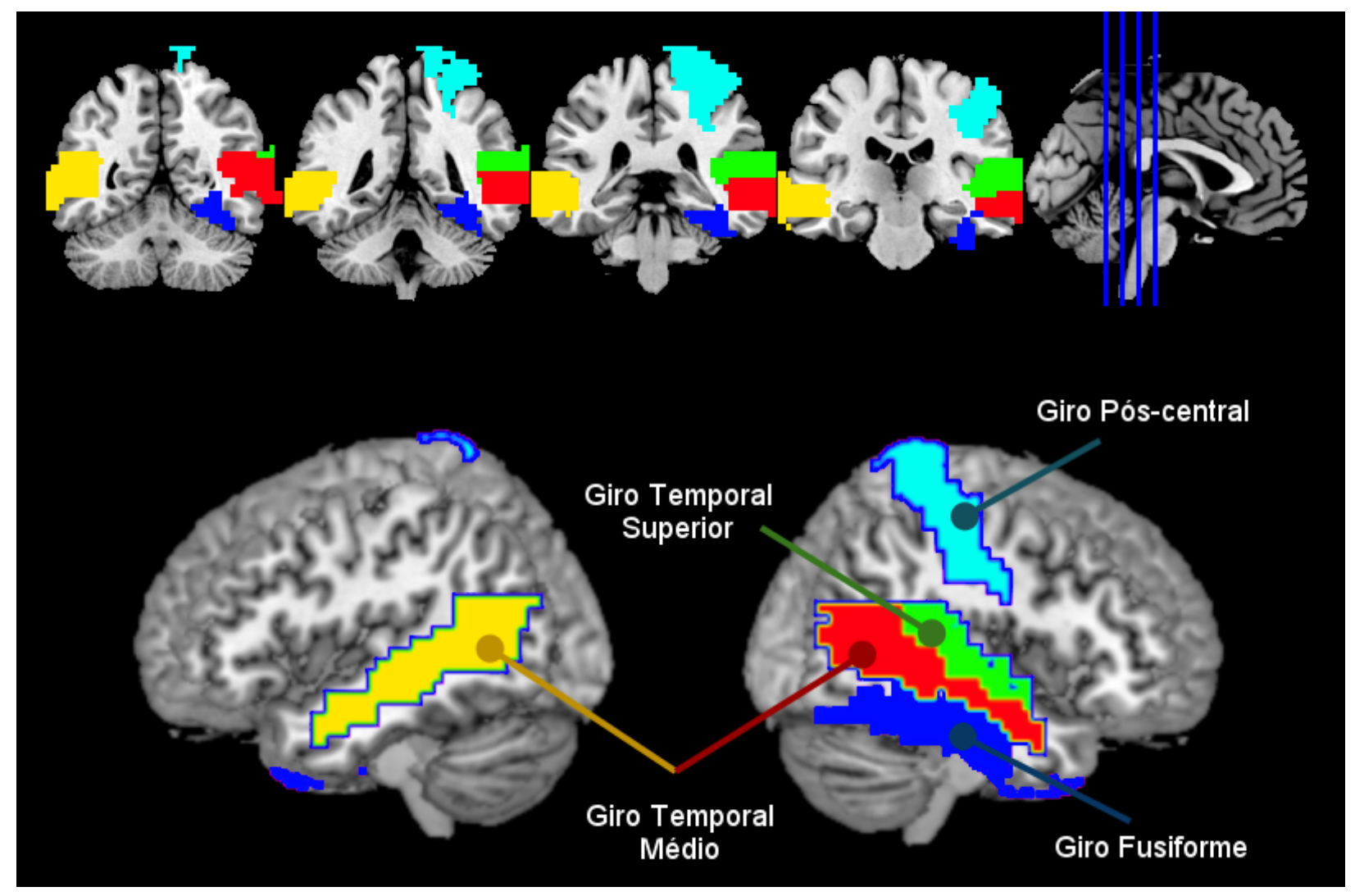

Figura 6.1: Localização cortical das ROIs cuja diferença de conectividade funcional com o cerebelo é significativa entre os grupos DT e TEA. 


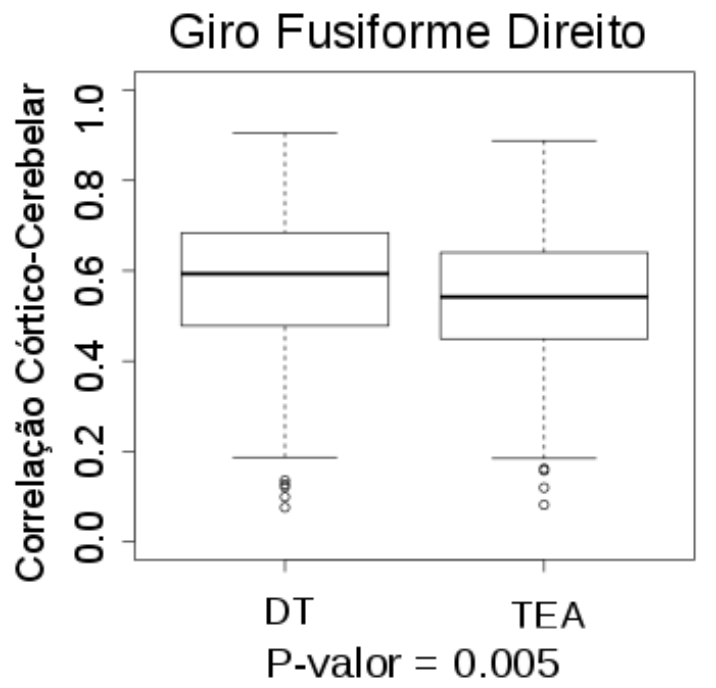

Giro Temporal Superior Direito

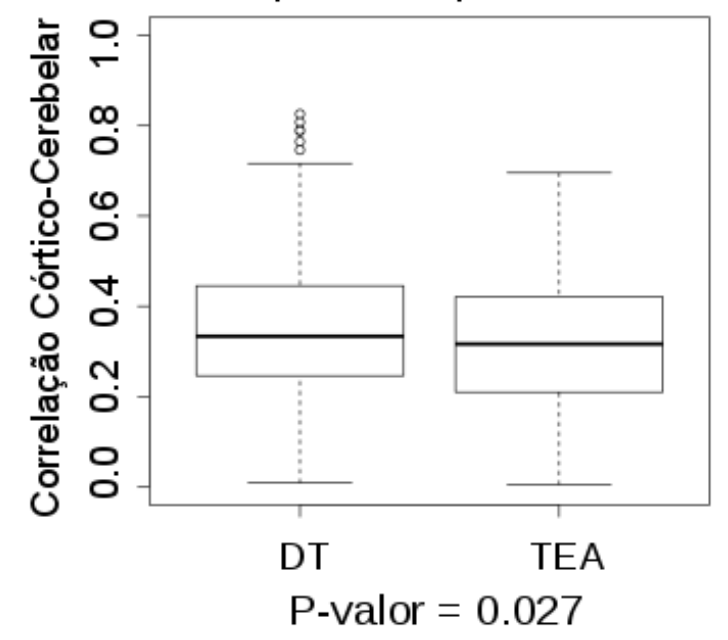

Giro Temporal Médio Esquerdo

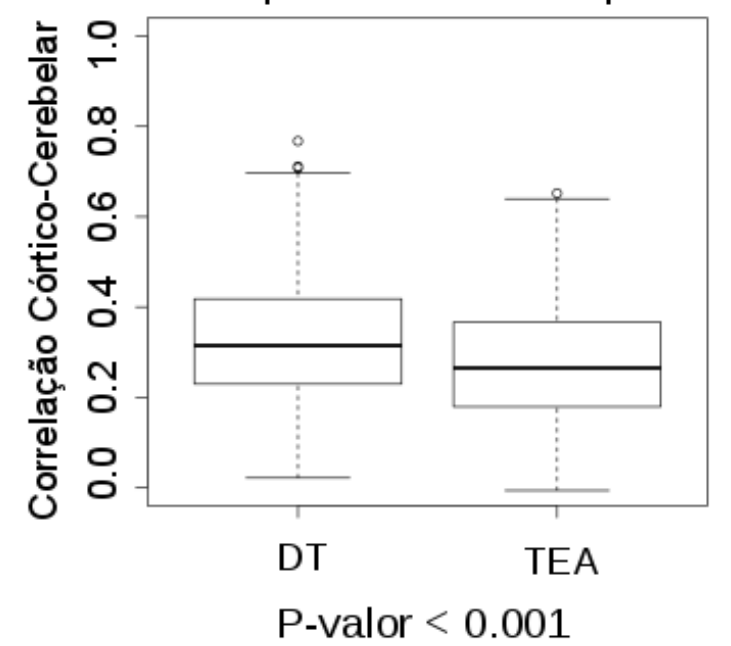

Giro Pós-Central Direito

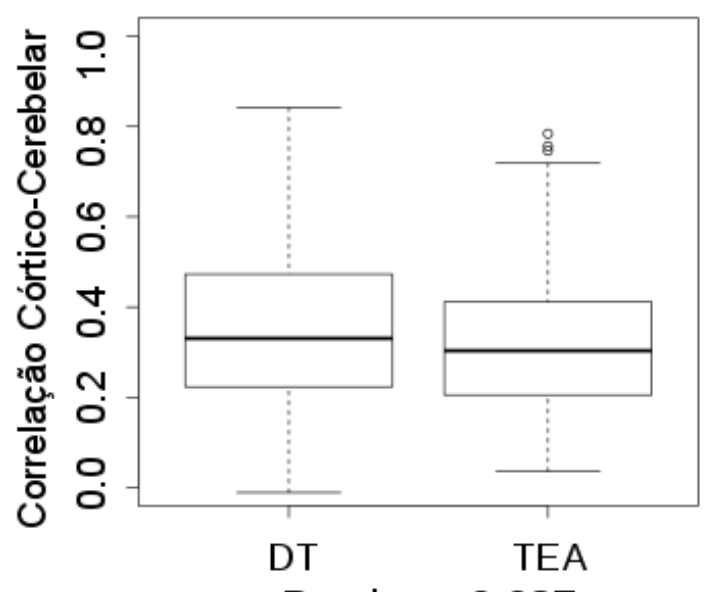

P-valor $=0.027$

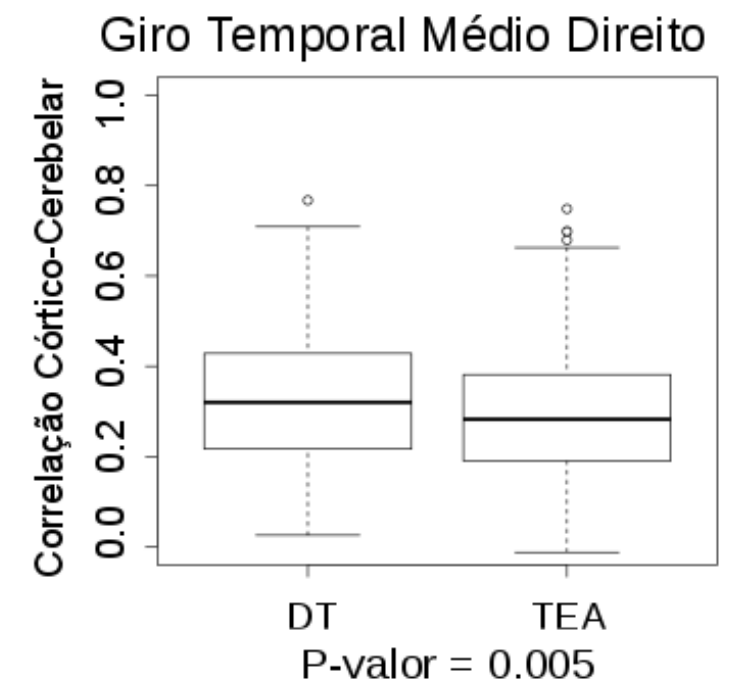

Figura 6.2: Comparação entre os grupos DT e TEA da conectividade funcional de cada uma das cinco ROIs de diferença estatisticamente significativa ( $p$-valor < 0.05) com o cerebelo. P-valor corrigido por FDR. 


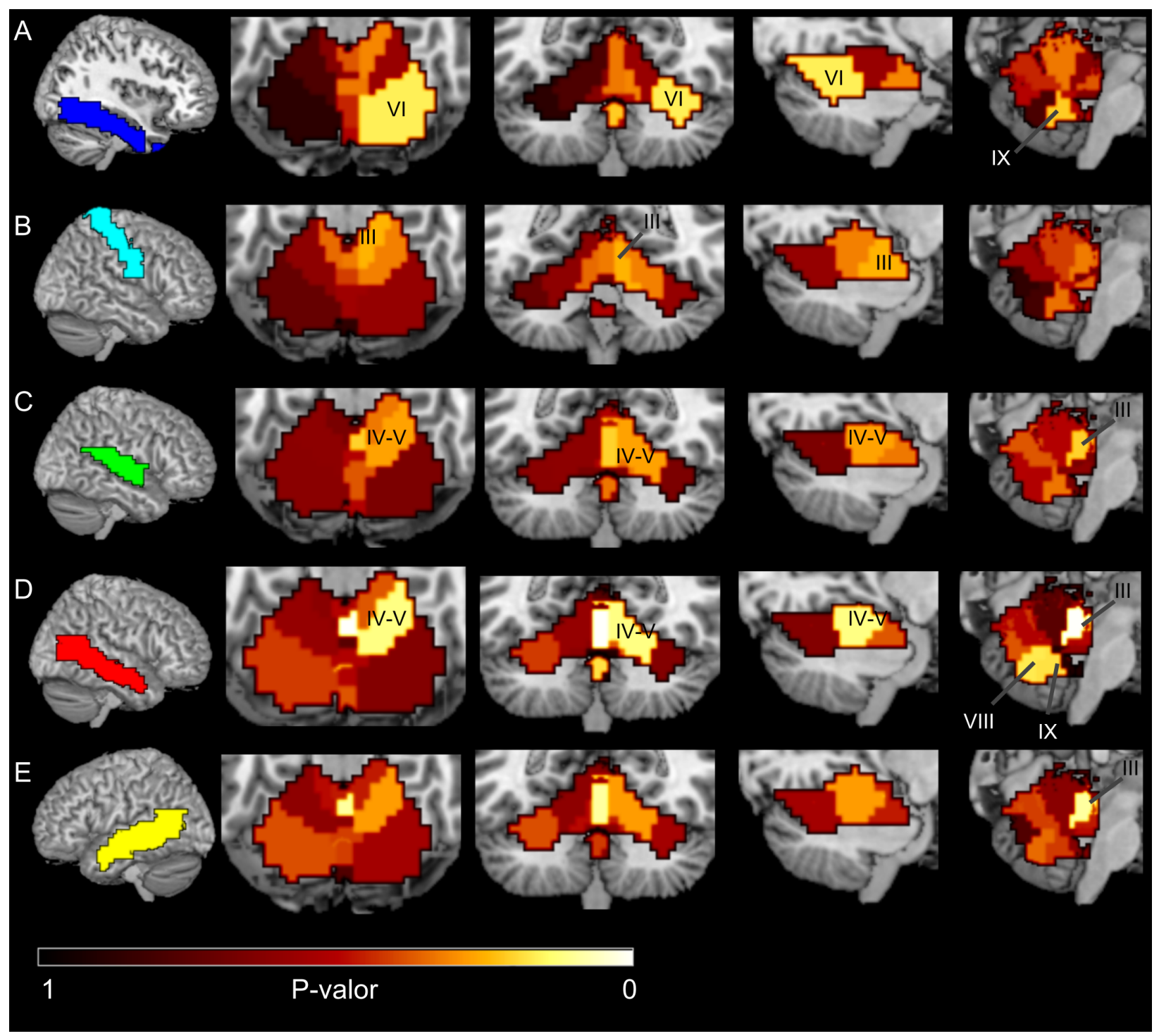

Figura 6.3: Mapa de calor indicando a diferença na conectividade funcional das ROIs do cerebelo entre os grupos DT e TEA. As ROIs cerebelares mais claras apresentam maior diferença no peso para a conectividade córtico-cerebelar entre os grupos (DT e TEA), as ROIs mais escuras apresentam menos diferença. A primeira coluna da esquerda contém a ROI do córtex sobre a qual o peso das ROIs do cerebelo se refere, as três colunas seguintes são cortes do cerebelo com maior foco nos hemisférios e a última coluna é um corte sagital do vérmis. As ROIs com indicação de número possuem p-valor não corrigido $<0.05$ para a diferença de peso entre os grupos. (A) Para o giro fusiforme direito, lóbulo direito VI e vérmis IX possuem maior diferença entre os grupos. (B) Para o giro pós-central, lóbulo direito III é o mais diferenciado entre os grupos. (C) Para o giro superior temporal direito, lóbulos $I V-V$ e vérmis III possuem maior diferença entre os grupos. (D) Para o giro temporal médio direito, lóbulo IV-V e vérmis III, VIII e IX possuem maior diferença entre os grupos. (E) Para o giro temporal médio esquerdo, o vérmis III é o mais diferente entre os grupos. 


\section{Capítulo 7}

\section{Discussão}

O exato funcionamento do cerebelo ainda é desconhecido, mas existe a hipótese de que a mesma funcionalidade que ele aplica na movimentação seja feita para várias outras informações vindas do córtex cerebral de forma que ele refina a informação e atua no processo de aprendizado de funções como comunicação verbal, planejamento de movimentos e emoções [Sch91, Sch10, SS10].

Por ser bastante relatado na literatura anomalias cerebelares relacionadas à casos de TEA $\left[\mathrm{FAA}^{+} 12, \mathrm{WSF}^{+} 09, \mathrm{LCS}^{+} 14\right]$ e com base em teorias que relacionam a conectividade cortico-cerebelar à cognição [Ito05, Ito08], nós formulamos a hipótese de que a conectividade córtico-cerebelar poderia ser diferenciada em TEA. Nossos achados confirmam a hipótese indicando conectividade córtico-cerebelar reduzida em TEA.

Até onde pudemos constatar, este é o primeiro estudo a investigar conectividade funcional córtico-cerebelar em TEA a utilizar exames fMRI da ordem de centenas de indivíduos. Exames de ressonância magnética funcional apresentam muitos artefatos por latência na resposta hemodinâmica, latência da coleta dos dados, erros por movimentação da cabeça e erros de normalização dos dados para a comparação dos indivíduos. Para minimizar os efeitos destes erros e aumentar o poder estatístico, é desejável utilizar uma grande quantidade de exames no estudo [Bux02, FM10].

Ao contrário dos estudos em que se desenvolve uma tarefa específica para estimular a ativação da região cerebral que se deseja estudar, em exames em estado de repouso não sabemos previamente a quais regiões cerebrais terão mais foco de ativação durante o exame. Para diminuir a chance de falsos positivos é desejável que os estudos de fMRI em estado de repouso analisem um grande número de indivíduos para estimar a conectividade cerebral com base nas flutuações de atividades intrínsecas [ENK16]. Isto reforça a importância de um estudo realizado com um banco de dados amplo como o ABIDE. 


\subsection{Hipoconectividade córtico-cerebelar em TEA}

A menor correlação córtico-cerebelar no TEA em comparação com indivíduos DT indica menor conectividade funcional entre cinco regiões do córtex integrantes do sistema sensorimotor, e cerebelo em indivíduos do grupo TEA [DG09], confirmando nossa hipótese inicial de conectividade córtico-cerebelar diferenciada em TEA. Nossos resultados estão de acordo com estudos post-mortem que indicam anomalias no cerebelo de indivíduos com TEA [WHP ${ }^{+} 80, \mathrm{RFS}^{+} 86, \mathrm{BLD}^{+}$98, KB02], estudos de DTI que indicam menor número de fibras entre o córtex cerebral e o cerebelo $\left[\mathrm{SKR}^{+} 10, \mathrm{HMKS}^{+} 13, \mathrm{JTB}^{+} 14\right]$ e estudos de fMRI baseados em tarefas que mostram menor ativação do cerebelo em TEA [MPS $\left.{ }^{+} 09\right]$.

As cinco regiões que foram identificadas apresentando menor conectividade córticocerebelar estão em quatro giros distintos, sendo três apenas do lado direito e um de ambos os lados. A relação de cada um dos quatro giros com os sintomas observados em casos de TEA será discutida nas próximas subseções.

\subsubsection{Giro Fusiforme}

O giro fusiforme é associado principalmente com reconhecimento de faces [KMC97, $\left.\mathrm{GBL}^{+} 14\right]$, reconhecimento de objetos familiares e formas [GTA ${ }^{+99}$. Existe evidência para uma menor quantidade de neurônios $\left[\mathrm{KPC}^{+} 08\right]$ e reduzida quantidade de receptores de neurotransmissores [OGB11] nesta região em indivíduos com TEA. Estudos tem demonstrado consistentemente diferentes padrões de ativação em regiões relacionados ao reconhecimento facial em TEA, incluindo o giro fusiforme. $\left[\mathrm{CDB}^{+} 00, \mathrm{SGK}^{+} 00\right]$.

\subsubsection{Giro Pós-central}

É parte do córtex sensorimotor primário e tem sido associado à funções sensoriais como: sensação tátil, percepção de temperatura, e percepção tátil [TTS ${ }^{+}$00]. Padrões de ativação diferenciados nesta região em TEA estão relacionados ao processamento de toques afetivos $\left[\mathrm{KYV}^{+} 16\right]$, empatia e compreensão social $\left[\mathrm{FCC}^{+} 14\right]$.

\subsubsection{Giro Temporal Superior}

O giro temporal superior é parte do córtex auditivo primário [RDA05]. Está relacionado à tarefas de identificação de sons, mas também é associado ao reconhecimento de faces e cognição social $\left[\mathrm{NOS}^{+} 01\right]$. Tem sido associado à esquizofrenia e psicose $\left[\mathrm{CMFP}^{+} 09\right]$. Em TEA, tem sido associado à dificuldades de percepção social [CFHF02, $\mathrm{ZMC}^{+}$06].

\subsubsection{Giro Temporal Médio}

O giro temporal médio tem sido associado ao reconhecimento de sons [MMA+01] e reconhecimento facial $\left[\mathrm{PAB}^{+} 98\right]$. Em TEA, tem sido observado menor ativação nesta área 
durante tarefas de percepção de sons complexos $\left[\mathrm{BBC}^{+} 03\right]$ e em processos de movimentação ocular [PMM05].

\subsubsection{Conectividade Funcional Cerebelar}

Apesar dos estudos mostrarem uma maior relação córtico-cerebelar contralateral, a relação ipsilateral também está presente [WBL13]. Nossos resultados sugerem uma conectividade funcional reduzida especialmente nos lóbulos III - VI na região dos hemisférios e lóbulos III, VIII e IX na região do vérmis. O lobo anterior do cerebelo (lóbulos I-V) costuma ser relacionado com funções sensorimotoras e o lobo posterior (VI-X) é mais relacionado à funções cognitivas $\left[\mathrm{OBT}^{+}\right.$10, $\mathrm{MPS}^{+}$09, SS10, SVS12]. Anomalias no vérmis cerebelar são constantemente relatadas na literatura como apresentando relação com o diagnóstico e intensidade de sintomas em TEA, sendo associado ao comportamento repetitivo [PC01, $\mathrm{CYCP}^{+} 88$ ]. Nossos resultados sugerem conectividade reduzida nas regiões vermais III, VIII e IX, que são menos associadas à hipoplasia em casos de TEA, porém, estudos tem mostrado hipoplasias e até hiperplasias variadas em TEA [CST $\left.{ }^{+94}\right]$.

\subsection{Limitações do Estudo}

Neste estudo dividimos o cérebro em várias pequenas regiões para fazer um estudo exploratório. Como consequência, ao corrigir para múltiplos testes limitamos bastante os resultados apenas aos que apresentavam grande consistência. É possível que alguns indivíduos outliers tenham prejudicado o resultado de outras regiões. No banco de dados utilizado não temos informações sobre sintomas apresentados pelos indivíduos do grupo TEA. Existem indivíduos de diferentes severidades e é esperado que os indivíduos do grupo apresentem sintomas bastante diferentes entre si, como normalmente se observa no espectro. Como o espectro autista é muito amplo, seria desejável selecionar apenas indivíduos que apresentam sintomas similares para o estudo. Por falta de informação sobre questionários de diagnósticos ADI ou ADOS não foi possível verificar correlação entre conectividade e severidade do diagnóstico. 


\section{Referências Bibliográficas}

[All88] D. A. Allen. Autistic spectrum disorders: clinical presentation in preschool children. Journal of Child Neurology, 3 Suppl:S48-56, 1988. 1, 4

[Asp44] Hans Asperger. Die ,autistischen psychopathen” im kindesalter. European Archives of Psychiatry and Clinical Neuroscience, 117(1):76-136, 1944. 3

[Asp77] H Asperger. The lived life. 50 years of pediatrics (in german). Padiatrie und Padologie, 12(3):214, 1977. 3

[Ass13] American Psychiatric Association. Diagnostic and Statistical Manual of Mental Disorders (DSM-5尺). American Psychiatric Pub, Maio 2013. 1, 3, 5, 30

[AVdVW $\left.{ }^{+} 99\right]$ Ruthie E. Amir, Ignatia B. Van den Veyver, Mimi Wan, Charles Q. Tran, Uta Francke e Huda Y. Zoghbi. Rett syndrome is caused by mutations in X-linked MECP2, encoding methyl-CpG-binding protein 2. Nature Genetics, 23(2):185-188, Outubro 1999. 4

[BBB $\left.{ }^{+} 15\right] \quad$ Oliver Baumann, Ronald J. Borra, James M. Bower, Kathleen E. Cullen, Christophe Habas, Richard B. Ivry, Maria Leggio, Jason B. Mattingley, Marco Molinari, Eric A. Moulton, Michael G. Paulin, Marina A. Pavlova, Jeremy D. Schmahmann e Arseny A. Sokolov. Consensus paper: the role of the cerebellum in perceptual processes. Cerebellum (London, England), 14(2):197-220, Abril 2015. 16, 17

$\left[\mathrm{BBC}^{+} 03\right] \quad$ Nathalie Boddaert, Pascal Belin, Nadia Chabane, Jean-Baptiste Poline, Catherine Barthélémy, Marie-Christine Mouren-Simeoni, Francis Brunelle, Yves Samson e Mônica Zilbovicius. Perception of complex sounds: abnormal pattern of cortical activation in autism. The American Journal of Psychiatry, 160(11):2057-2060, Novembro 2003. 41

[BH80] R.Clifford Blair e J.J. Higgins. The Power of t and Wilcoxon Statistics: A Comparison. Evaluation Review, 4(5):645-656, Outubro 1980. 34

[BK85] M. Bauman e T. L. Kemper. Histoanatomic observations of the brain in early infantile autism. Neurology, 35(6):866-874, Junho 1985. 8, 16

[BK05] Margaret L. Bauman e Thomas L. Kemper. Neuroanatomic observations of the brain in autism: a review and future directions. International Journal of Developmental Neuroscience, 23(2-3):183-187, Abril 2005. 2, 8, 12, 16

$\left[\mathrm{BKC}^{+} 11\right]$ Randy L. Buckner, Fenna M. Krienen, Angela Castellanos, Julio C. Diaz e B. T. Thomas Yeo. The organization of the human cerebellum estimated by intrinsic functional connectivity. Journal of Neurophysiology, 106(5):23222345, Novembro 2011. 11, 13 
$\left[\mathrm{BLD}^{+98}\right.$ A. Bailey, P. Luthert, A. Dean, B. Harding, I. Janota, M. Montgomery, M. Rutter e P. Lantos. A clinicopathological study of autism. Brain: A Journal of Neurology, 121 ( Pt 5):889-905, Maio 1998. 12, 40

[BMB74] G. G. Ball, D. J. Micco e G. G. Berntson. Cerebellar stimulation in the rat: complex stimulation-bound oral behaviors and self-stimulation. Physiology $\& 6$ Behavior, 13(1):123-127, Julho 1974. 8

[Bol98] E. R. Bolte. Autism and Clostridium tetani. Medical Hypotheses, 51(2):133144, Agosto 1998. 1, 4

[BPM73] Gary G. Berntson, Samuel J. Potolicchio e Neal E. Miller. Evidence for Higher Functions of the Cerebellum: Eating and Grooming Elicited by Cerebellar Stimulation in Cats. Proceedings of the National Academy of Sciences of the United States of America, 70(9):2497-2499, Setembro 1973. 8

[Buc13] Randy L. Buckner. The Cerebellum and Cognitive Function: 25 Years of Insight from Anatomy and Neuroimaging. Neuron, 80(3):807-815, Outubro 2013. $7,10,11,13,14$

[Bux02] Richard B. Buxton. Introduction to Functional Magnetic Resonance Imaging: Principles and Techniques. Cambridge University Press, Janeiro 2002. GoogleBooks-ID: pi3ogRUXxgYC. 20, 39

[BYHH95] B. Biswal, F. Z. Yetkin, V. M. Haughton e J. S. Hyde. Functional connectivity in the motor cortex of resting human brain using echo-planar MRI. Magnetic Resonance in Medicine, 34(4):537-541, Outubro 1995. 11, 28

$\left[\mathrm{CAR}^{+} 76\right] \quad$ Irving S. Cooper, Ismail Amin, Manuel Riklan, Joseph M. Waltz e Tung Pui Poon. Chronic Cerebellar Stimulation in Epilepsy: Clinical and Anatomical Studies. Archives of Neurology, 33(8):559-570, Agosto 1976. 8

$\left[\mathrm{CDB}^{+} 00\right] \quad$ H. D. Critchley, E. M. Daly, E. T. Bullmore, S. C. Williams, T. Van Amelsvoort, D. M. Robertson, A. Rowe, M. Phillips, G. McAlonan, P. Howlin e D. G. Murphy. The functional neuroanatomy of social behaviour: changes in cerebral blood flow when people with autistic disorder process facial expressions. Brain: A Journal of Neurology, 123 ( Pt 11):2203-2212, Novembro 2000. 40

$\left[\mathrm{CDVBC}^{+}\right.$16] Alessandro Crippa, Giuseppe Del Vecchio, Silvia Busti Ceccarelli, Maria Nobile, Filippo Arrigoni e Paolo Brambilla. Cortico-Cerebellar Connectivity in Autism Spectrum Disorder: What Do We Know So Far? Frontiers in Psychiatry, 7, Fevereiro 2016. 2, 16

[CFHF02] Fulvia Castelli, Chris Frith, Francesca Happé e Uta Frith. Autism, Asperger syndrome and brain mechanisms for the attribution of mental states to animated shapes. Brain, 125(8):1839-1849, Agosto 2002. 40

[Chr16] Deborah L. Christensen. Prevalence and Characteristics of Autism Spectrum Disorder Among Children Aged 8 Years - Autism and Developmental Disabilities Monitoring Network, 11 Sites, United States, 2012. MMWR. Surveillance Summaries, 65, 2016. 4 
[CMFP ${ }^{+}$09] Nicolas A. Crossley, Andrea Mechelli, Paolo Fusar-Poli, Matthew R. Broome, Pall Matthiasson, Louise C. Johns, Elvira Bramon, Lucia Valmaggia, Steven C.R. Williams e Philip K. McGuire. Superior temporal lobe dysfunction and frontotemporal dysconnectivity in subjects at risk of psychosis and in first-episode psychosis. Human Brain Mapping, 30(12):4129-4137, Dezembro 2009. 40

[Com31] M Combettes. Absence complète du cervelet, des pédoncules postérieurs et de la protubérance cérébrale chez une jeune fille morte dans sa onzième année. Bull Soc Anat Paris, 5:148-57, 1831. 1, 8

[CST $\left.{ }^{+} 94\right] \quad$ E. Courchesne, O. Saitoh, J. P. Townsend, R. Yeung-Courchesne, G. A. Press, A. J. Lincoln, R. H. Haas e L. Schriebman. Cerebellar hypoplasia and hyperplasia in infantile autism. Lancet (London, England), 343(8888):63-64, Janeiro 1994. 16, 41

$\left[\mathrm{CTM}^{+} 15\right]$ Emma Colvert, Beata Tick, Fiona McEwen, Catherine Stewart, Sarah R. Curran, Emma Woodhouse, Nicola Gillan, Victoria Hallett, Stephanie Lietz, Tracy Garnett, Angelica Ronald, Robert Plomin, Frühling Rijsdijk, Francesca Happé e Patrick Bolton. Heritability of Autism Spectrum Disorder in a UK Population-Based Twin Sample. JAMA psychiatry, 72(5):415-423, Maio 2015. 4

$\left[\mathrm{CYCP}^{+88}\right.$ E. Courchesne, R. Yeung-Courchesne, G. A. Press, J. R. Hesselink e T. L. Jernigan. Hypoplasia of cerebellar vermal lobules VI and VII in autism. The New England Journal of Medicine, 318(21):1349-1354, Maio 1988. 2, 5, 8, 16, 41

[DG09] Jessica S. Damoiseaux e Michael D. Greicius. Greater than the sum of its parts: a review of studies combining structural connectivity and resting-state functional connectivity. Brain Structure and Function, 213(6):525-533, Junho 2009. 40

[DM58] Robert S. Dow e Giuseppe Moruzzi. The Physiology and Pathology of the Cerebellum. U of Minnesota Press, 1958. Google-Books-ID: 1Ddmi1Wu5uYC. 8

[DMYL $\left.{ }^{+} 14\right]$ Adriana Di Martino, Chao-Gan Yan, Qingyang Li, Erin Denio, Francisco X. Castellanos, Kaat Alaerts, Jeffrey S. Anderson, Michal Assaf, Susan Y. Bookheimer, Mirella Dapretto, Ben Deen, Sonja Delmonte, Ilan Dinstein, Birgit Ertl-Wagner, Damien A. Fair, Louise Gallagher, Daniel P. Kennedy, Christopher L. Keown, Christian Keysers, Janet E. Lainhart, Catherine Lord, Beatriz Luna, Vinod Menon, Nancy Minshew, Christopher S. Monk, Sophia Mueller, Ralph-Axel Müller, Mary Beth Nebel, Joel T. Nigg, Kirsten O'Hearn, Kevin A. Pelphrey, Scott J. Peltier, Jeffrey D. Rudie, Stefan Sunaert, Marc Thioux, J. Michael Tyszka, Lucina Q. Uddin, Judith S. Verhoeven, Nicole Wenderoth, Jillian L. Wiggins, Stewart H. Mostofsky e Michael P. Milham. The Autism Brain Imaging Data Exchange: Towards Large-Scale Evaluation of the Intrinsic Brain Architecture in Autism. Molecular psychiatry, 19(6):659-667, Junho 2014. 2 
[Dow74] R. S. Dow. Some novel concepts of cerebellar physiology. The Mount Sinai Journal of Medicine, New York, 41(1):103-119, Fevereiro 1974. 8

$\left[\mathrm{DRM}^{+}\right.$10] Geraldine Dawson, Sally Rogers, Jeffrey Munson, Milani Smith, Jamie Winter, Jessica Greenson, Amy Donaldson e Jennifer Varley. Randomized, Controlled Trial of an Intervention for Toddlers With Autism: The Early Start Denver Model. Pediatrics, 125(1):e17-e23, Janeiro 2010. 5

[DS15] Anila M. D'Mello e Catherine J. Stoodley. Cerebro-cerebellar circuits in autism spectrum disorder. Frontiers in Neuroscience, 9, 2015. 12

$\left[\mathrm{EBC}^{+}\right.$06] Thomas J. Eluvathingal, Michael E. Behen, Harry T. Chugani, James Janisse, Bruno Bernardi, Pulak Chakraborty, Csaba Juhasz, Otto Muzik e Diane C. Chugani. Cerebellar Lesions in Tuberous Sclerosis Complex: Neurobehavioral and Neuroimaging Correlates. Journal of Child Neurology, 21(10):846-851, Outubro 2006. 17

[ENK16] Anders Eklund, Thomas E. Nichols e Hans Knutsson. Cluster failure: Why fMRI inferences for spatial extent have inflated false-positive rates. Proceedings of the National Academy of Sciences of the United States of America, 113(28):7900-7905, Julho 2016. 39

$\left[\mathrm{FAA}^{+} 12\right] \quad$ S. Hossein Fatemi, Kimberly A. Aldinger, Paul Ashwood, Margaret L. Bauman, Charles D. Blaha, Gene J. Blatt, Abha Chauhan, Ved Chauhan, Stephen R. Dager, Price E. Dickson, Annette M. Estes, Dan Goldowitz, Detlef H. Heck, Thomas L. Kemper, Bryan H. King, Loren A. Martin, Kathleen J. Millen, Guy Mittleman, Matthew W. Mosconi, Antonio M. Persico, John A. Sweeney, Sara J. Webb e John P. Welsh. Consensus paper: pathological role of the cerebellum in autism. Cerebellum (London, England), 11(3):777-807, Setembro 2012. 2, 5, 16, 17, 39

$\left[\mathrm{FCC}^{+} 14\right] \quad$ Yang-Teng Fan, Chenyi Chen, Shih-Chuan Chen, Jean Decety e Yawei Cheng. Empathic arousal and social understanding in individuals with autism: evidence from fMRI and ERP measurements. Social Cognitive and Affective Neuroscience, 9(8):1203-1213, Agosto 2014. 40

[FDS12] Sydney M. Finegold, Julia Downes e Paula H. Summanen. Microbiology of regressive autism. Anaerobe, 18(2):260-262, Abril 2012. 4

[FHR $\left.{ }^{+} 02\right] \quad$ S. Hossein Fatemi, Amy R. Halt, George Realmuto, Julie Earle, David A. Kist, Paul Thuras e Amelia Merz. Purkinje cell size is reduced in cerebellum of patients with autism. Cellular and Molecular Neurobiology, 22(2):171-175, Abril 2002. 2, 5, 12, 16

[Flo24] M Flourens. Recherches experimentales sur les animaux vertebres, 1824. 1, 7

[FM10] Scott H. Faro e Feroze B. Mohamed, editors. BOLD fMRI. Springer New York, New York, NY, 2010. 19, 21, 27, 39

[FMS ${ }^{+}$02] Sydney M. Finegold, Denise Molitoris, Yuli Song, Chengxu Liu, Marja-Liisa Vaisanen, Ellen Bolte, Maureen McTeague, Richard Sandler, Hannah Wexler, Elizabeth M. Marlowe, Matthew D. Collins, Paul A. Lawson, Paula Summanen, Mehmet Baysallar, Thomas J. Tomzynski, Erik Read, Eric Johnson, 
Rial Rolfe, Palwasha Nasir, Haroun Shah, David A. Haake, Patricia Manning e Ajay Kaul. Gastrointestinal Microflora Studies in Late-Onset Autism. Clinical Infectious Diseases, 35(Supplement 1):S6-S16, Setembro 2002. 4

[FWH ${ }^{+}$96] Karl J. Friston, Steven Williams, Robert Howard, Richard S. J. Frackowiak e Robert Turner. Movement-Related effects in fMRI time-series. Magnetic Resonance in Medicine, 35(3):346-355, Março 1996. 24

$\left[\mathrm{GBL}^{+} 14\right]$ Avniel Singh Ghuman, Nicolas M. Brunet, Yuanning Li, Roma O. Konecky, John A. Pyles, Shawn A. Walls, Vincent Destefino, Wei Wang e R. Mark Richardson. Dynamic encoding of face information in the human fusiform gyrus. Nature Communications, 5:5672, Dezembro 2014. 40

[Gli92] M. Glickstein. The cerebellum and motor learning. Current Opinion in Neurobiology, 2(6):802-806, Dezembro 1992. 2, 15

[GLN02] Christopher R. Genovese, Nicole A. Lazar e Thomas Nichols. Thresholding of Statistical Maps in Functional Neuroimaging Using the False Discovery Rate. NeuroImage, 15(4):870-878, Abril 2002. 33

[GSV09] M. Glickstein, P. Strata e J. Voogd. Cerebellum: history. Neuroscience, 162(3):549-559, Setembro 2009. 7, 10

$\left[\mathrm{GTA}^{+}\right.$99] Isabel Gauthier, Michael J. Tarr, Adam W. Anderson, Pawel Skudlarski e John C. Gore. Activation of the middle fusiform 'face area' increases with expertise in recognizing novel objects. Nature Neuroscience, 2(6):568-573, Junho 1999. 40

[HMKS ${ }^{+}$13] Ryuzo Hanaie, Ikuko Mohri, Kuriko Kagitani-Shimono, Masaya Tachibana, Junji Azuma, Junko Matsuzaki, Yoshiyuki Watanabe, Norihiko Fujita e Masako Taniike. Altered microstructural connectivity of the superior cerebellar peduncle is related to motor dysfunction in children with autistic spectrum disorders. Cerebellum (London, England), 12(5):645-656, Outubro 2013. 40

[HTM+95] T. Hashimoto, M. Tayama, K. Murakawa, T. Yoshimoto, M. Miyazaki, M. Harada e Y. Kuroda. Development of the brainstem and cerebellum in autistic patients. Journal of Autism and Developmental Disorders, 25(1):1-18, Fevereiro 1995. 2, 5

$\left[\mathrm{IBH}^{+} 01\right] \quad$ P. Indefrey, C. M. Brown, F. Hellwig, K. Amunts, H. Herzog, R. J. Seitz e P. Hagoort. A neural correlate of syntactic encoding during speech production. Proceedings of the National Academy of Sciences of the United States of America, 98(10):5933-5936, Maio 2001. 27

[Ito02] Masao Ito. Historical Review of the Significance of the Cerebellum and the Role of Purkinje Cells in Motor Learning. Annals of the New York Academy of Sciences, 978(1):273-288, Dezembro 2002. 12, 13

[Ito05] Masao Ito. Bases and implications of learning in the cerebellum-adaptive control and internal model mechanism. Progress in Brain Research, 148:95109, 2005. 15, 39

[Ito06] Masao Ito. Cerebellar circuitry as a neuronal machine. Progress in Neurobiology, 78(3-5):272-303, Abril 2006. 2, 8, 13 
[Ito08] Masao Ito. Control of mental activities by internal models in the cerebellum. Nature Reviews. Neuroscience, 9(4):304-313, Abril 2008. 2, 39

[IYO64] M. Ito, M. Yoshida e K. Obata. Monosynaptic inhibition of the intracerebellar nuclei induced rom the cerebellar cortex. Experientia, 20(10):575-576, Outubro 1964. 8

[Jol13] I. T. Jolliffe. Principal Component Analysis. Springer Science \& Business Media, Março 2013. 32

$\left[\mathrm{JTB}^{+} 14\right] \quad$ Jeong-Won Jeong, Vijay N. Tiwari, Michael E. Behen, Harry T. Chugani e Diane C. Chugani. In vivo detection of reduced Purkinje cell fibers with diffusion MRI tractography in children with autistic spectrum disorders. Frontiers in Human Neuroscience, 8, Fevereiro 2014. 40

$\left[\mathrm{K}^{+} 43\right] \quad$ Leo Kanner et al. Autistic disturbances of affective contact. 1943. 3

[KB02] T. L. Kemper e M. L. Bauman. Neuropathology of infantile autism. Molecular Psychiatry, 7 Suppl 2:S12-13, 2002. 8, 40

[KGBT14] Recep Keşli, Cem Gökçen, Ufuk Buluğ e Yüksel Terzi. Investigation of the relation between anaerobic bacteria genus clostridium and late-onset autism etiology in children. Journal of Immunoassay $\& 5$ Immunochemistry, 35(1):101109, 2014. 4

[KMC97] Nancy Kanwisher, Josh McDermott e Marvin M. Chun. The Fusiform Face Area: A Module in Human Extrastriate Cortex Specialized for Face Perception. Journal of Neuroscience, 17(11):4302-4311, Junho 1997. 40

$\left[\mathrm{KPC}^{+} 08\right] \quad$ Imke A. J. van Kooten, Saskia J. M. C. Palmen, Patricia von Cappeln, Harry W. M. Steinbusch, Hubert Korr, Helmut Heinsen, Patrick R. Hof, Herman van Engeland e Christoph Schmitz. Neurons in the fusiform gyrus are fewer and smaller in autism. Brain, 131(4):987-999, Abril 2008. 40

[KS45] Seymour S Kety e Carl F Schmidt. The determination of cerebral blood flow in man by the use of nitrous oxide in low concentrations. American Journal of Physiology-Legacy Content, 143(1):53-66, 1945. 19

[KS00] R. M. Kelly e P. L. Strick. Rabies as a transneuronal tracer of circuits in the central nervous system. Journal of Neuroscience Methods, 103(1):63-71, Novembro 2000. 10, 14

[KS03] Roberta M. Kelly e Peter L. Strick. Cerebellar loops with motor cortex and prefrontal cortex of a nonhuman primate. The Journal of Neuroscience: The Official Journal of the Society for Neuroscience, 23(23):8432-8444, Setembro 2003. 2,14

[KUK $\left.{ }^{+} 14\right] \quad$ Rajesh K. Kana, Lucina Q. Uddin, Tal Kenet, Diane Chugani e Ralph-Axel Müller. Brain connectivity in autism. Frontiers in Human Neuroscience, 8:349, 2014. 16 
$\left[\mathrm{KYV}^{+} 16\right]$ Martha D. Kaiser, Daniel Y.-J. Yang, Avery C. Voos, Randi H. Bennett, Ilanit Gordon, Charlotte Pretzsch, Danielle Beam, Cara Keifer, Jeffrey Eilbott, Francis McGlone e Kevin A. Pelphrey. Brain Mechanisms for Processing Affective (and Nonaffective) Touch Are Atypical in Autism. Cerebral Cortex, 26(6):2705-2714, Junho 2016. 40

[LCS $\left.{ }^{+} 14\right] \quad$ Catherine Limperopoulos, Gevorg Chilingaryan, Nancy Sullivan, Nicolas Guizard, Richard L. Robertson e Adré J. du Plessis. Injury to the Premature Cerebellum: Outcome is Related to Remote Cortical Development. Cerebral Cortex (New York, NY), 24(3):728-736, Março 2014. 2, 5, 39

[LED16] Helen Lazaratou, Marina Economou e Dimitris Dikeos. The necessity of early intervention in autism. The Journal of Pediatrics, 0(0), Dezembro 2016. 4

[Lei10] Henrietta C. Leiner. Solving the mystery of the human cerebellum. Neuropsychology Review, 20(3):229-235, Setembro 2010. 8

[LLD86] H. C. Leiner, A. L. Leiner e R. S. Dow. Does the cerebellum contribute to mental skills? Behavioral Neuroscience, 100(4):443-454, Agosto 1986. 8

[Log03] Nikos K. Logothetis. The underpinnings of the BOLD functional magnetic resonance imaging signal. The Journal of Neuroscience: The Official Journal of the Society for Neuroscience, 23(10):3963-3971, Maio 2003. 20

[MCK14] Jose O. Maximo, Elyse J. Cadena e Rajesh K. Kana. The implications of brain connectivity in the neuropsychology of autism. Neuropsychology Review, 24(1):16-31, Março 2014. 2

[MMA $\left.{ }^{+} 01\right]$ Philippe P. Maeder, Reto A. Meuli, Michela Adriani, Anne Bellmann, Eleonora Fornari, Jean-Philippe Thiran, Antoine Pittet e Stéphanie Clarke. Distinct Pathways Involved in Sound Recognition and Localization: A Human fMRI Study. NeuroImage, 14(4):802-816, Outubro 2001. 40

[MPS ${ }^{+}$09] Stewart H. Mostofsky, Stephanie K. Powell, Daniel J. Simmonds, Melissa C. Goldberg, Brian Caffo e James J. Pekar. Decreased connectivity and cerebellar activity in autism during motor task performance. Brain, página awp088, Abril 2009. 40, 41

[MS94] F. A. Middleton e P. L. Strick. Anatomical evidence for cerebellar and basal ganglia involvement in higher cognitive function. Science (New York, N.Y.), 266(5184):458-461, Outubro 1994. 10

[MS00] Frank A Middleton e Peter L Strick. Basal ganglia and cerebellar loops: motor and cognitive circuits. Brain Research Reviews, 31(2-3):236-250, Março 2000. 10

[MS01] F. A. Middleton e P. L. Strick. Cerebellar projections to the prefrontal cortex of the primate. The Journal of Neuroscience: The Official Journal of the Society for Neuroscience, 21(2):700-712, Janeiro 2001. 10

$\left[\mathrm{MSK}^{+}{ }^{11}\right]$ Ralph-Axel Müller, Patricia Shih, Brandon Keehn, Janae R. Deyoe, Kelly M. Leyden e Dinesh K. Shukla. Underconnected, but How? A Survey of Functional Connectivity MRI Studies in Autism Spectrum Disorders. Cerebral Cortex (New York, NY), 21(10):2233-2243, Outubro 2011. 16 
[MU82] Mortimer Mishkin e Leslie G. Ungerleider. Contribution of striate inputs to the visuospatial functions of parieto-preoccipital cortex in monkeys. Behavioural Brain Research, 6(1):57-77, Setembro 1982. 27

[Nor14] Maryam Noroozian. The role of the cerebellum in cognition: beyond coordination in the central nervous system. Neurologic Clinics, 32(4):1081-1104, Novembro 2014. 2, 5, 7

[NOS $\left.{ }^{+} 01\right] \quad$ Jin Narumoto, Tomohisa Okada, Norihiro Sadato, Kenji Fukui e Yoshiharu Yonekura. Attention to emotion modulates fMRI activity in human right superior temporal sulcus. Cognitive Brain Research, 12(2):225-231, Outubro 2001. 40

$\left[\mathrm{OBT}^{+}{ }^{10}\right] \quad$ Jill X. O'Reilly, Christian F. Beckmann, Valentina Tomassini, Narender Ramnani e Heidi Johansen-Berg. Distinct and overlapping functional zones in the cerebellum defined by resting state functional connectivity. Cerebral Cortex (New York, N.Y.: 1991), 20(4):953-965, Abril 2010. 11, 13, 41

[OGB11] Adrian L. Oblak, Terrell T. Gibbs e Gene J. Blatt. Reduced GABAA receptors and benzodiazepine binding sites in the posterior cingulate cortex and fusiform gyrus in autism. Brain Research, 1380:218-228, Março 2011. 40

[OLKT90] S. Ogawa, T. M. Lee, A. R. Kay e D. W. Tank. Brain magnetic resonance imaging with contrast dependent on blood oxygenation. Proceedings of the National Academy of Sciences of the United States of America, 87(24):98689872, Dezembro 1990. 18

[OLNG90] S. Ogawa, T. M. Lee, A. S. Nayak e P. Glynn. Oxygenation-sensitive contrast in magnetic resonance image of rodent brain at high magnetic fields. Magnetic Resonance in Medicine, 14(1):68-78, Abril 1990. 18

$\left[\mathrm{OTM}^{+} 92\right] \quad$ S. Ogawa, D. W. Tank, R. Menon, J. M. Ellermann, S. G. Kim, H. Merkle e K. Ugurbil. Intrinsic signal changes accompanying sensory stimulation: functional brain mapping with magnetic resonance imaging. Proceedings of the National Academy of Sciences of the United States of America, 89(13):59515955, Julho 1992. 18, 21

[PAB $\left.{ }^{+} 98\right] \quad$ Aina Puce, Truett Allison, Shlomo Bentin, John C. Gore e Gregory McCarthy. Temporal Cortex Activation in Humans Viewing Eye and Mouth Movements. Journal of Neuroscience, 18(6):2188-2199, Março 1998. 40

[PBS ${ }^{+}$12] Jonathan D. Power, Kelly A. Barnes, Abraham Z. Snyder, Bradley L. Schlaggar e Steven E. Petersen. Spurious but systematic correlations in functional connectivity MRI networks arise from subject motion. NeuroImage, 59(3):2142-2154, Fevereiro 2012. 24

[PC36] Linus Pauling e Charles D. Coryell. The Magnetic Properties and Structure of Hemoglobin, Oxyhemoglobin and Carbonmonoxyhemoglobin. Proceedings of the National Academy of Sciences of the United States of America, 22(4):210216, Abril 1936. 18

[PC01] Karen Pierce e Eric Courchesne. Evidence for a cerebellar role in reduced exploration and stereotyped behavior in autism. Biological Psychiatry, 49(8):655-664, Abril 2001. 41 
$\left[\mathrm{PFP}^{+} 88\right] \quad$ Steven E Petersen, Peter T Fox, Michael I Posner, Mark Mintun e Marcus E Raichle. Positron emission tomographic studies of the cortical anatomy of single-word processing. Nature, 331(6157):585-589, 1988. 2, 7, 9

$\left[\mathrm{PFP}^{+} 89\right] \quad$ SE Petersen, PT Fox, MI Posner, M Mintun e M Raichle. Positron emission tomography studies of the processing of single words. Journal of Cognitive Neuroscience, 1:153-170, 1989. 2, 7, 9, 10

[PMM05] Kevin A. Pelphrey, James P. Morris e Gregory McCarthy. Neural basis of eye gaze processing deficits in autism. Brain, 128(5):1038-1048, Maio 2005. 41

[PMN11] Russell A. Poldrack, Jeanette A. Mumford e Thomas E. Nichols. Handbook of Functional MRI Data Analysis. Cambridge University Press, Agosto 2011. Google-Books-ID: OywOnwEACAAJ. 21, 22, 23, 24, 26, 30

[Ram06] Narender Ramnani. The primate cortico-cerebellar system: anatomy and function. Nature Reviews Neuroscience, 7(7):511-522, Julho 2006. 2, 14, 15

[RDA05] Teemu Rinne, Alexander Degerman e Kimmo Alho. Superior temporal and inferior frontal cortices are activated by infrequent sound duration decrements: an fMRI study. NeuroImage, 26(1):66-72, Maio 2005. 40

[RFS $\left.{ }^{+} 86\right] \quad$ E. R. Ritvo, B. J. Freeman, A. B. Scheibel, T. Duong, H. Robinson, D. Guthrie e A. Ritvo. Lower Purkinje cell counts in the cerebella of four autistic subjects: initial findings of the UCLA-NSAC Autopsy Research Report. The American Journal of Psychiatry, 143(7):862-866, Julho 1986. 2, 12, 16, 40

[Rog96] S. J. Rogers. Brief report: early intervention in autism. Journal of Autism and Developmental Disorders, 26(2):243-246, Abril 1996. 5

[RS90] C. S. Roy e C. S. Sherrington. On the Regulation of the Blood-supply of the Brain. The Journal of Physiology, 11(1-2):85-158.17, Janeiro 1890. 18

[SBJ13] Jeroen C. W. Siero, Alex Bhogal e J. Martijn Jansma. Blood Oxygenation Level-dependent/Functional Magnetic Resonance Imaging: Underpinnings, Practice, and Perspectives. PET clinics, 8(3):329-344, Julho 2013. 20, 21, 22

[Sch91] J. D. Schmahmann. An emerging concept. The cerebellar contribution to higher function. Archives of Neurology, 48(11):1178-1187, Novembro 1991. 2, $13,16,39$

[Sch98] J. D. Schmahmann. Dysmetria of thought: clinical consequences of cerebellar dysfunction on cognition and affect. Trends in Cognitive Sciences, 2(9):362371, Setembro 1998. 16

[Sch04] Jeremy D. Schmahmann. Disorders of the cerebellum: ataxia, dysmetria of thought, and the cerebellar cognitive affective syndrome. The Journal of Neuropsychiatry and Clinical Neurosciences, 16(3):367-378, 2004. 2, 16

[Sch10] Jeremy D. Schmahmann. The role of the cerebellum in cognition and emotion: personal reflections since 1982 on the dysmetria of thought hypothesis, and its historical evolution from theory to therapy. Neuropsychology Review, 20(3):236-260, Setembro 2010. 2, 7, 8, 9, 10, 11, 14, 16, 39 
$\left[\mathrm{SDP}^{+} 00\right] \quad J e r e m y$ D. Schmahmann, Julien Doyon, Michael Petrides, Alan C. Evans e Arthur W. Toga. MRI Atlas of the Human Cerebellum. Academic Press, Agosto 2000. Google-Books-ID: pm9YQssN0NIC. 11

[SE51] R. Snider e E. Eldred. Electro-anatomical studies on cerebro-cerebellar connections in the cat. The Journal of Comparative Neurology, 95(1):1-16, Agosto 1951. 8

[SE52] R. S. Snider e E. Eldred. Cerebrocerebellar relationships in the monkey. Journal of Neurophysiology, 15(1):27-40, Janeiro 1952. 7, 8, 13

[SGK $\left.{ }^{+} 00\right] \quad$ R. T. Schultz, I. Gauthier, A. Klin, R. K. Fulbright, A. W. Anderson, F. Volkmar, P. Skudlarski, C. Lacadie, D. J. Cohen e J. C. Gore. Abnormal ventral temporal cortical activity during face discrimination among individuals with autism and Asperger syndrome. Archives of General Psychiatry, 57(4):331340, Abril 2000. 40

[Sha14] Alia Shakiba. The role of the cerebellum in neurobiology of psychiatric disorders. Neurologic Clinics, 32(4):1105-1115, Novembro 2014. 2, 5, 7

[SKR ${ }^{+}$10] Lalitha Sivaswamy, Ajay Kumar, Deepa Rajan, Michael Behen, Otto Muzik, Diane Chugani e Harry Chugani. A diffusion tensor imaging study of the cerebellar pathways in children with autism spectrum disorder. Journal of Child Neurology, 25(10):1223-1231, Outubro 2010. 40

[SM76] R. S. Snider e A. Maiti. Cerebellar contributions to the Papez circuit. Journal of Neuroscience Research, 2(2):133-146, 1976. 8

[SMV09] Jeremy D. Schmahmann, Jason MacMore e Mark Vangel. Cerebellar stroke without motor deficit: Clinical evidence for motor and non-motor domains within the human cerebellum. Neuroscience, 162(3):852-861, Setembro 2009. 10

[SPE ${ }^{+}$07] Saasha Sutera, Juhi Pandey, Emma L. Esser, Michael A. Rosenthal, Leandra B. Wilson, Marianne Barton, James Green, Sarah Hodgson, Diana L. Robins, Thyde Dumont-Mathieu e Deborah Fein. Predictors of optimal outcome in toddlers diagnosed with autism spectrum disorders. Journal of Autism and Developmental Disorders, 37(1):98-107, Janeiro 2007. 5

[SS44] Ray S Snider e Averill Stowell. Receiving areas of the tactile, auditory, and visual systems in the cerebellum. Journal of Neurophysiology, 1944. 8, 9

[SS98] J. D. Schmahmann e J. C. Sherman. The cerebellar cognitive affective syndrome. Brain, 121(4):561-579, Abril 1998. 2, 7, 16

[SS10] Catherine J. Stoodley e Jeremy D. Schmahmann. Evidence for topographic organization in the cerebellum of motor control versus cognitive and affective processing. Cortex, 46(7):831-844, Julho 2010. 13, 39, 41

[SSGJA09] Julia A. Scott, Cynthia Mills Schumann, Beth L. Goodlin-Jones e David G. Amaral. A comprehensive volumetric analysis of the cerebellum in children and adolescents with autism spectrum disorder. Autism Research: Official Journal of the International Society for Autism Research, 2(5):246-257, Outubro 2009. 16 
[SVS12] Catherine J. Stoodley, Eve M. Valera e Jeremy D. Schmahmann. Functional topography of the cerebellum for motor and cognitive tasks: an fMRI study. NeuroImage, 59(2):1560-1570, Janeiro 2012. 13, 41

[Swa14] Larry Swanson. Neuroanatomical Terminology: A Lexicon of Classical Origins and Historical Foundations. Oxford University Press, Julho 2014. GoogleBooks-ID: 5LLEBgAAQBAJ. 1

$\left[\mathrm{TMLP}^{+}\right.$02] N. Tzourio-Mazoyer, B. Landeau, D. Papathanassiou, F. Crivello, O. Etard, N. Delcroix, B. Mazoyer e M. Joliot. Automated anatomical labeling of activations in SPM using a macroscopic anatomical parcellation of the MNI MRI single-subject brain. NeuroImage, 15(1):273-289, Janeiro 2002. 26, 30

[TTS $\left.{ }^{+} 00\right] \quad$ K. Takeda, K. Takeda, Y. Shozawa, M. Sonoo, T. Shimizu e T. Kaminaga. The rostrocaudal gradient for somatosensory perception in the human postcentral gyrus. Journal of Neurology, Neurosurgery \& Psychiatry, 69(5):692-693, Novembro 2000. 40

[Vid14] Maciel Calebe Vidal. Análise da estrutura de clusterização das redes de conectividade funcional do cérebro para investigar as bases das desordens do espectro autista. Dissertação de Mestrado, universidade de São Paulo, São Paulo, 2014. 21, 24, 25, 26, 29

[WBL13] Danhong Wang, Randy L. Buckner e Hesheng Liu. Cerebellar asymmetry and its relation to cerebral asymmetry estimated by intrinsic functional connectivity. Journal of Neurophysiology, 109(1):46-57, Janeiro 2013. 41

$\left[\mathrm{WHP}^{+} 80\right] \quad$ R. S. Williams, S. L. Hauser, D. P. Purpura, G. R. DeLong e C. N. Swisher. Autism and mental retardation: neuropathologic studies performed in four retarded persons with autistic behavior. Archives of Neurology, 37(12):749753, Dezembro 1980. 40

[WSF ${ }^{+}$09] Sara Jane Webb, Bobbi-Faun Sparks, Seth D. Friedman, Dennis W. W. Shaw, Jay Giedd, Geraldine Dawson e Stephen R. Dager. Cerebellar vermal volumes and behavioral correlates in children with autism spectrum disorder. Psychiatry Research: Neuroimaging, 172(1):61-67, Abril 2009. 2, 5, 39

$\left[\mathrm{ZBL}^{+}\right.$09] Lonnie Zwaigenbaum, Susan Bryson, Catherine Lord, Sally Rogers, Alice Carter, Leslie Carver, Kasia Chawarska, John Constantino, Geraldine Dawson, Karen Dobkins, Deborah Fein, Jana Iverson, Ami Klin, Rebecca Landa, Daniel Messinger, Sally Ozonoff, Marian Sigman, Wendy Stone, Helen TagerFlusberg e Nurit Yirmiya. Clinical assessment and management of toddlers with suspected autism spectrum disorder: insights from studies of high-risk infants. Pediatrics, 123(5):1383-1391, Maio 2009. 5

$\left[\mathrm{ZMC}^{+}\right.$06] Monica Zilbovicius, Isabelle Meresse, Nadia Chabane, Francis Brunelle, Yves Samson e Nathalie Boddaert. Autism, the superior temporal sulcus and social perception. Trends in Neurosciences, 29(7):359-366, Julho 2006. 40 